\title{
DATOS SOBRE LA FLORA Y VEGETACIÓN DE LA SERRANÍA DE RONDA (MÁLAGA, ESPAÑA)
}

\author{
Andrés V. PÉREZ LATORRE, Patricia NAVAS, David NAVAS, \\ Yolanda GIL y Baltasar CABEZUDO
}

\begin{abstract}
RESUMEN. Datos sobre la flora y vegetación de la Serranía de Ronda (Málaga, España). Se ha realizado un estudio de la flora y vegetación del Parque Natural de la Sierra de las Nieves (Málaga, España). Como resultado se han catalogado 1400 táxones, de los que en este trabajo destacamos 36, por ser especies protegidas, primeras citas y endémicas de la zona. Se propone una nueva combinación: Ulex baeticus subsp. bourgaeanus. Se han inventariado un total de 78 asociaciones y comunidades. Se describen como nuevos sintáxones una alianza (Pino pinastri-Juniperion phoeniceae), 12 asociaciones, 9 subasociaciones y 1 combinación nueva. Se reconocen 6 series climatófilas de las que dos son de alcornocales (Quercus suber), una de encinares (Quercus rotundifolia), una de robledales (Quercus pyrenaica), una de quejigales (Quercus alpestris) y una de sabinares-enebrales (Juniperus sabina). Otras 5 series son edafoxerófilas de las que dos corresponden a pinsapares (Abies pinsapo), dos a sabinares (Juniperus phoenicea) y una a pinares (Pinus pinaster). Además reconocemos 5 series edafohigrófilas: 1 de fresnedas (Fraxinus angustifolia), dos de saucedas (Salix pedicellata) y 2 de adelfares (Nerium oleander). Se presenta como resultado final el esquema sintaxonómico completo del Parque.
\end{abstract}

Palabras clave. Flora, vegetación, series, Serranía de Ronda, Málaga, Andalucía, España.

SUMMARY. New data on flora and vegetation in the Serranía de Ronda (Málaga, Andalusia, Spain). A floristic and phytosociologial study has been done in the Natural Park Sierra de las Nieves, placed in Málaga (Andalusia, Spain). A total of 1.400 taxa have been recorded, fom which we have pointed out and commented 36, due to their biological value as endemisms, rare, protected or endemic species or new records in the studied area. One new taxonomical combination is proposed: Ulex baeticus subsp. bourgaeanus. A total of 78 associations and communities have been recorded. New sintaxa are described: one alliance (Pino pinastri-Juniperion phoeniceae), 12 associations, 9 subassociations and one new combination. The 6 climactic series described with their main tree species, soil and bioclimatic range are the following: two series of Quercus suber (termo-mesomediterranean on schists), one of Quercus rotundifolia (mesomediterranean on limestones), one of Quercus pyrenaica (mesomediterranean on schists), one of Quercus alpestris (supramediterranean on limestones) and one of Juniperus sabina (oromediterranean on limestones). The 5 edaphoxeric series described with their main tree species, soil and bioclimatic range are the following: two series of Abies pinsapo (meso-supramediterranean on perdotite rocks and dolomite), two series of Juniperus phoenicea (termo-meso-supramediterranean on marble, dolomite and limestones) and one of Pinus pinaster (termo-mesomediterranean on peridotite rocks). The 5 riverine edaphoseries described with their main tree species, soil and water-level range are the following: one of Fraxinus angustifolia (summer-droughted rivers on limestones), two of Salix pedicellata (summer-droughted rivers on peridotite rocks, schists and limestones) and two of Nerium oleander (seasonal streams, on peridotite rocks, schists and limestones). Finally, the complete sintaxonomic scheme, with new sintaxa, combinations, hierarchycity and comments on the associations and communities is given.

Key words. Flora, vegetation, series, Serranía de Ronda, Málaga, Andalusia, Spain.

Trabajo realizado en el marco del convenio 807/031050 firmado entre la Consejería de Medio Ambiente de la Junta de Andalucía y la Universidad de Málaga (Dpto. Biología Vegetal) y el proyecto AMB 98-1017. 


\section{INTRODUCCIÓN}

La Ley 2/1989 de 18 de Julio (BOJA 60) aprobó el inventario de Espacios Naturales Protegidos de Andalucía, entre ellos el Parque Natural Sierra de las Nieves (Málaga). La creación de esta figura de protección fuerza la necesidad de conocer la estructura del espacio en cuestión, como paso previo y necesario para una gestión adecuada. Desde un punto de vista vegetal, el conocimiento de dicha estructura implica un estudio inicial sobre las condiciones ecológicas del espacio, tales como el suelo y el clima, expresado este último en unidades bioclimáticas. Posteriormente se hace preciso conocer en profundidad la biodiversidad vegetal existente, al menos en aquellos grupos que marcan y caracterizan las unidades paisajísticas. Este conocimiento permitirá un análisis de las agrupaciones de los elementos florísticos en unidades de vegetación (asociaciones, series, comunidades, etc.) y, sobre todo, una política adecuada de conservación de especies y ecosistemas.

Durante la realización de la base cartográfica y de inventariación, se han obtenido una serie de resultados florísticos y fitosociológicos que consideramos novedosos no sólo para el Parque sino para el conjunto de la Serranía de Ronda (Málaga y Cádiz), novedades marcadas por el hecho de que la mayoría de los trabajos botánicos anteriores se han centrado en el dominio de los pinsapares, dejando sin estudiar otras zonas que consideramos, al menos, igualmente importantes.

\section{MATERIAL Y MÉTODOS}

\section{Área de estudio}

El Parque Natural de la Sierra de las Nieves se localiza al SW de la provincia de Málaga (Andalucía) y constituye la porción más elevada y geológicamente compleja de la Serranía de Ronda, extremo más occidental de las Cordilleras Béticas. Las altitudes oscilan entre $\operatorname{los} 200 \mathrm{~m}$. y $1919 \mathrm{~m}$. Geomorfológicamente el territorio está constituido por alineaciones montañosas (Sierra de las Nieves, de Tolox, Parda, Hidalga) surcadas por profundos valles (río Verde, río Turón, río Grande). El Parque está distribuido entre los términos municipales de Ronda, Yunquera, Tolox, Monda, Istán y Parauta.

Litológicamente los materiales pertenecen a cuatro grandes tipos de sustratos: peridotitas al S, micaesquistos y gneises al SE, calizas y margas en el NW y dolomías al N. Los tipos de suelos del Parque son los siguientes: litosoles en zonas rocosas (ocupados por pastizales), entisoles generalmente azonales (con vegetación edafoxerófila), inceptisoles en fuertes pendientes (áreas de bosque) y, más escasos, alfisoles y mollisoles en zonas llanas (bosque o praderas) y vertisoles en áreas arcillosas (frecuentemente encharcadas).

La bioclimatología del Parque viene marcada por las diferencias altitudinales (1700 metros de desnivel) y su correspondiente variación termométrica. Por ello encontramos en el área de estudio 4 pisos bioclimáticos (Rivas Martínez 1987): termomediterráneo de 200 a 600 (900) m., mesomediterráneo de 600 (900) a 1200 (1400) m., supramediterráneo de $1200(1400)$ a $1700(1800)$ m. y oromediterráneo de 1700 (1800) a 1919 m. La orientación y marcada topografía del Parque hacen que los límites indicados para los pisos presenten una variación muy acusada, reflejada en los ecosistemas vegetales.

La precipitación es, en general, elevada (entre 1000 y $1600 \mathrm{~mm}$ ) pero siempre marcada por una acusada sequía estival. Se reconocen tres ombrotipos (Rivas Martínez et al.,1991): subhúmedo en el NW, húmedo en zonas de media altitud e hiperhúmedo en las zonas más elevadas. Las heladas en invierno son frecuentes en toda la zona, así como las nieves 
por encima de los $1600 \mathrm{~m}$. Condiciones topográficas y edáficas modulan sustancialmente tanto la cantidad de precipitación como la persistencia de la misma en el suelo.

La Sierra de las Nieves participa de las siguientes unidades fitogeográficas (Nieto Caldera et al., 1991; Pérez Latorre et al.; 1996, Cabezudo et al., 1998):

Reino Holártico

Región Mediterránea

\section{Subregión Mediterránea Occidental}

Superprovincia Iberomarroquí-Atlántica Provincia Bética

Sector Rondeño

1. Subsector Rondense [sierras calizo-dolomíticas]

Sector Bermejense

2. Subsector Bermejense [sierras peridotíticas]

Provincia Tingitano-Onubo-Algarviense Sector Aljíbico

3. Subsector Marbellí [sierras silíceas]

\section{Metodología}

A fin de no perder información florística ni fitosociológica de los numerosos ecosistemas existentes, se realizaron recolecciones durante un año completo y repartidas, en función de la edafología y climatología, por todo el areal del Parque. Para la identificación del material recolectado se utilizaron las obras generales sobre la flora ibérica y de Andalucía; para los grupos conflictivos se utilizaron monografías o se enviaron a especialistas, a los que agradecemos la colaboración prestada. Todo el material recolectado ha sido depositado en el herbario de la Universidad de Málaga (MGC). En el capítulo de resultados hemos incluido sólo un listado de aquellos táxones protegidos, raros o amenazados, citándose, para cada uno, el biotipo, corología y la posición bioclimática y fitosociológica en el Parque. En algunos casos se hacen las observaciones que creemos pertinentes.

Para el análisis de la vegetación se utilizó el método fitosociológico de Braun-Blanquet (1979) y el propuesto por Rivas Martínez (1987) para las series de vegetación y paisaje vegetal. En el capítulo de resultados, presentamos las novedades sintaxonómicas, las series de vegetación y el esquema sintaxonómico completo.

\section{RESULTADOS}

\section{Flora de interés}

Abies pinsapo Boiss.

Macrofanerófito. Rondeño, Bermejense, Aljíbico (Marbellí). Termo a oromediterráneo húmedo-hiperhúmedo. Alcornocales, pinsapares, quejigares, encinares, sabinares y enebrales oromediterráneos (Quercion suberis, PaeonioAbietienion, Aceri-Quercion fagineae, PaeonioQuercenion, Pino-Juniperion phoeniceae, PinoJuniperion sabinae).

Arenaria capillipes (Boiss.) Boiss.

Terófito. Bermejense. Meso-supramediterráneo subhúmedo-húmedo. Pastizales anuales sobre serpentinas (Omphalodion commutatae).

\section{Armeria colorata Pau}

Caméfito. Bermejense. Meso-supramediterráneo húmedo. Comunidades rupícolas y de taludes (Andryalo-Crambion filiformis).

Armeria villosa Girard subsp. carratracensis (Bernis) Nieto Feliner

Caméfito. Bermejense. Mesomediterráneo húmedo. Comunidades rupícolas y de taludes (Andryalo-Crambion filiformis).

Astragalus granatensis Lam. subsp. granatensis

Caméfito pulviniforme. Suribérico. Oromediterráneo hiperhúmedo. Piornales sobre dolomías (Xeroacantho-Erinaceion). 
Astragalus sempervirens Lam. subsp. nevadensis (Boiss.) P. Monts.

Caméfito pulviniforme. Nevadense y Rondeño. Oro-supramediterráneo húmedo-hiperhúmedo. Piornales xeroacánticos calcícolas (XeroacanthoErinaceion).

\section{Athamantha vayredana (Font Quer) Pardo}

Hemicriptófito. Suribérico. Mesosupramediterráneo húmedo. Comunidades rupícolas xerófilas (Poterion ancistroides).

\section{Atropa baetica Willk.}

Hemicriptófito. Ibero-norteafricano. Supramediterráneo húmedo. Pinsapares (PaeonioAbietienion).

Centaurea clementei Boiss. ex DC.

Caméfito. Suribérico-norteafricano. Mesosupramediterráneo húmedo. Comunidades rupícolas heliófilas (Poterion ancistroides).

\section{Centranthus nevadensis Boiss.}

Caméfito. Bético-Rifeño. Supramediterráneo húmedo. Comunidades rupícolas umbrófilas (Saxifragion camposii). En sustrato distinto al que ocupan las poblaciones clásicas de Sierra Nevada.

\section{Convolvulus boissieri Steud. subsp. boissieri}

Caméfito pulviniforme. Bético. Supramediterráneo húmedo. Tomillares dolomitícolas (Andryalion agardhii).

\section{Cotoneaster granatensis (Guss.) C. Koch}

Microfanerófito. Bético. Supramediterráneo húmedo-hiperhúmedo. Espinares caducifolios (Lonicero-Berberidion hispanicae).

\section{Crataegus granatensis Boiss.}

Microfanerófito. Bético. Supraoromediterráneo hiperhúmedo. Espinares caducifolios (Lonicero-Berberidion hispanicae).

Cytisus fontanesii Spach subsp.plumosus (Boiss.) Nyman

Caméfito. Rondense. Meso-supramediterráneo subhúmedo-húmedo. Matorrales sobre calizas (Micromerio-Coridothymion capitati).

\section{Galium pulvinatum Boiss.}

Caméfito pulviniforme. Rondense, Mijense.
Meso-supramediterráneo húmedo. Comunidades rupícolas sobre dolomías (Saxifragion camposii).

\section{Galium viridiflorum Boiss. \& Reuter}

Caméfito lianescente. Bermejense, Almijarense. Termo-mesomediterráneo húmedo. Juncales, saucedas y adelfares sobre serpentinas (Molinio-Holoschoenion, Rubo-Nerion, Salicion salvifoliae).

Genista longipes DC. subsp. viciosoi Talavera y Cabezudo

Nanofanerófito pulviniforme. Bético. Supramediterráneo húmedo. Piornales hiperxerófilos sobre dolomías (XeroacanthoErinaceion).

\section{Ilex aquifolium L.}

Microfanerófito. Eurasia y Norte de Africa. Supramediterráneo húmedo. Especie de la que sólo tenemos referencias orales de su presencia en el Parque.

Juniperus communis L. subsp. hemisphaerica (K Presl) Nyman

Microfanerófito postrado. MediterráneoEuropeo. Oro-supramediterráneo superior hiperhúmedo. Enebrales y sabinares de alta montaña mediterránea (Pino-Juniperion sabinae).

Juniperus phoenicea L. subsp. phoenicea

Microfanerófito. Mediterráneo-Macaronésico. Termo a supra (oro) mediterráneo. Sabinares edafoxerófilos y pinsapares dolomitícolas (PinoJuniperion phoeniceae, Paeonio-Abietienion).

\section{Juniperus sabina L.}

Microfanerófito postrado. Mediterráneo. Orosupramediterráneo superior hiperhúmedo. Enebrales y sabinares de alta montaña mediterránea (PinoJuniperion sabinae).

Leucanthemum arundanum (Boiss.) Cuatrec.

Hemicriptófito. Suribérico. Supraoromediterráneo húmedo-hiperhúmedo. Gleras fijas y rocas (Thlaspietalia rotundifolii).

Narcissus bugei (Fern. Casas) Fern. Casas

Geófito. Bético. Supramediterráneo húmedo. Praderas, juncales (Phalaridetalia, Plantaginetalia) 
y más rara vez matorrales (LavanduloEchinospartion).

\section{Potentilla petrophila Boiss.}

Caméfito pulviniforme. Bético. Supramediterráneo húmedo. Comunidades rupícolas orófilas (Saxifragion camposii).

Quercus alpestris Boiss. Macrofanerófito.

Rondense. Supramediterráneo húmedo-hiperhúmedo. Quejigales con arces y serbales (Aceri-Quercion fagineae).

\section{Quercus pyrenaica Willd.}

Macrofanerófito. Ibero-norteafricano y SE de Francia. Mesomediterráneo húmedo. Robledales (Quercenion pyrenaicae).

\section{Salvia lavandulifolia Vahl.}

Caméfito. Ibero-norteafricana. Supramediterráneo húmedo. Matorrales dolomitícolas (LavanduloEchinospartion boissieri). La población localizada podría pertenecer a la subsp. vellerea (Cuatrec.) Rivas Goday.

Sarcocapnos baetica (Boiss. \& Reut.) Nyman subsp. baetica

Caméfito. Bético. Supra-mesomediterráneo húmedo. Comunidades espeluncícolas umbrófilas (Sarcocapnetalia).

Silene boryi Boiss.

Hemicriptófito. Ibero-norteafricano. Oromediterráneo hiperhúmedo. Canchales (Thlaspietalia rotundifolii).

\section{Silene fernandezii Jeanm.}

Caméfito. Bermejense. Mesomediterráneo húmedo. Comunidades rupícolas y de taludes (Andryalo-Crambion filiformis).

\section{Taxus baccata L.}

Macrofanerófito. Euroasiático y Norteafricano. Supra-oromediterráneo húmedohiperhúmedo. Pinsapares, quejigales y enebrales de alta montaña (Paeonio-Abietienion, Aceri-Quercion fagineae, Pino-Juniperion sabinae).

Teucrium afrum (Emb. \& Maire) Pau \& Font Quer subsp. afrum
Caméfito. Rifeño y Rondeño. Mesomediterráneo húmedo. Encinares con alcornoques y sus pastizales esciohumícolas (Paeonio-Quercenion rotundifoliae, Origanion virentis).

Trifolium repens L. subsp. nevadense (Boiss.) D.

E. Coombe

Hemicriptófito. Bético. Supraoromediterráneo hiperhúmedo. Pastizales higrófilos de dolinas nivales y fuentes (MolinioArrhenateretea).

Ulex baeticus Boiss. subsp. bourgaeanus (Webb)

Pérez Latorre \& Cabezudo comb. et stat. nov. Ulex bourgaeanus Webb Otia hispan. 39: 1830 (Basión.)

Nanofanerófito pulviniforme. Rondense. Supra-oromediterráneo húmedo. Piornales hiperxerófilos de dolomías (XeroacanthoErinaceion).

\section{Vella spinosa Boiss.}

Caméfito pulviniforme. Suribérico. Supraoromediterráneo húmedo-hiperhúmedo. Piornales hiperxerófilos de dolomías (XeroacanthoErinaceion).

\section{Veronica fontqueri Pau.}

Caméfito. Rondeño y Gadorense. Supraoromediterráneo húmedo-hiperhúmedo. Piornales pulviniformes (Xeroacantho-Erinaceion).

\section{Novedades sintaxonómicas}

Pino pinastri-Juniperion phoeniceae Pérez Latorre y Cabezudo all. nova

[Sintypus: Pino pinastri-Quercetum cocciferae Cabezudo, Nieto Caldera y Pérez Latorre 1989 in Acta Bot. Malacitana, 14: 291-293].

Vegetación fanerofítica edafoxerófila, fundamentalmente magnesícola, que se desarrolla sobre peridotitas y dolomías, de origen paleomediterráneo y distribución al menos Bética, caracterizada por la dominancia arbórea y/o arbustiva de gimnospermas: Pinus halepensis, Pinus pinaster, Pinus nigra, Abies pinsapo, Juniperus phoenicea, Juniperus 
oxycedrus, Ephedra fragilis, siempre en territorios cuya potencialidad climática corresponde a formaciones de planifolios (Quercus). Pueden ser componentes característicos de estas formaciones otros fanerófitos de índole relíctica como Ceratonia siliqua, Buxus balearica o Buxus sempervirens. Esta alianza incluiría provisionalmente (en Andalucía) 7 asociaciones, anteriormente en Rhamno-Quercion cocciferae, AsparagoRhamnion y Aceri-Quercion fagineae:

- Pino pinastri-Quercetum cocciferae Cabezudo, Nieto Caldera y Pérez Latorre 1989 [Bermejense, serpentinícola, Pinus pinaster, Juniperus oxycedrus].

- Pino halepensis-Juniperetum phoeniceae ass. nova [Rondeña, dolomitícola, Juniperus phoenicea, Pinus halepensis, Juniperus oxycedrus].

- Rhamno myrtifolii-Juniperetum phoeniceae Molero Mesa y Pérez Raya 1987 [Bética, dolomitícola, Juniperus phoenicea, Abies pinsapo, Pinus nigra, Pinus pinaster, Buxus sempervirens].

- Paeonio broteroi-Abietetum pinsaponis Asensi y Rivas Martínez 1976 [Rondeña, calcícola-dolomitícola, Abies pinsapo, Juniperus phoenicea, Juniperus oxycedrus, Pinus halepensis].

- Cneoro triccoci-Buxetum balearicae Rivas Goday y Rivas Martínez 1968 [Almijarense, dolomitícola, Pinus halepensis, Juniperus oxycedrus, Juniperus phoenicea, Buxus balearica].

- Rhamno velutini-Quercetum cocciferae Nieto, Pérez Sanz y Cabezudo 1987 [Mijense, dolomitícola, Pinus halepensis, Ephedra fragilis, Juniperus oxycedrus].

- Bunio macucae-Abietetum pinsaponis (Asensi y Rivas Martínez 1976) Rivas Martínez 1987 [Bermejense, serpentinícola, Abies pinsapo].

La alianza se incluye de manera provisional en Pistacio-Rhamnetalia alaterni, a la espera de una revisión completa de la vegetación edafoxerófila caracterizada por gimnospermas. Esta revisión debería incluir el estudio de los sabinares del Alto Atlas marroquí descritos por Quézel y Barbero (1981, 1990) bajo los epítetos de Junipero thuriferaeQuercetalia rotundifoliae y Ephedro majorisJuniperetalia phoeniceae y los del Mediterráneo Oriental de Junipero excelsaeQuercion calliprini Barbero y Quézel 1979.

En la Península Ibérica existen otras asociaciones edafoxerófilas incluíbles en está alianza, como el Buxo-Juniperetum phoeniceae Rivas Martínez 1969 y Rhamno lycioidisJuniperetum phoeniceae Rivas Martínez y López González 1976. La subalianza Tetraclino-Juniperenion phoeniceae Barbero, Quézel y Rivas Martínez 1981, incluida por sus autores en Pistacio-Rhamnetalia podría circunscribirse a la nueva alianza propuesta. La alianza Juniperion turbinatae Rivas Martínez (1975) 1987 podría tener cabida también en Pino-Juniperion phoeniceae como vegetación edafoxerófila sobre arenas. Probablemente la clase Pino-Juniperetea podría también acoger esta nueva alianza, dentro del suborden mediterráneo PinoJuniperenalia, ampliando la acepción ecológica y dinámica de la clase.

\section{Pino halepensis-Juniperetum phoeniceae}

Pérez Latorre y Cabezudo ass. nova

[Tabla 1, sintypus inv. $\mathrm{n}^{\circ} 3$ ]

\section{juniperetosum phoeniceae}

Sabinar-pinar edafoxerófilo dolomitícola con algarrobos, termomediterráneo bajo ombroclima subhúmedo-húmedo. Asociación caracterizada por Juniperus phoenicea, Pinus halepensis, Juniperus oxycedrus y Ceratonia siliqua, junto con especies diferenciales tales como Rhamnus velutinus y siendo frecuente la presencia de Ulex baeticus como territorial. Su distribución es rondense (sector Rondeño). Asociación que sustituye al ChamaeropoJuniperetum phoeniceae Rivas Martínez 1989 en el sector Rondeño y ya denunciada en parte por Ceballos y Vicioso (1933) como Pinetum 
halepensis. Constituyen la etapa climácica de la serie de los sabinares termófilos del PinoJunipereto phoeniceae S.

genistetosum haenseleri Pérez Latorre y Cabezudo comb. nova

[Chamaeropo-Juniperetum phoeniceae genistetosum haenseleri Nieto, Pérez Latorre y Cabezudo 1991]. Subasociación exclusiva del subsector Mijense (sector Rondeño) caracterizada por el endemismo Genista haenseleri.

Rhamno myrtifolii-Juniperetum phoeniceae Molero Mesa y Pérez Raya 1987 abietetosum pinsaponis Pérez Latorre y Cabezudo subass. nova.

[Tabla 2, sintypus inv. $\mathrm{n}^{\circ} 1$ ]

Sabinares con pinsapos, edafoxerófilos, basófilos (calizas, dolomías y mármoles), meso-supramediterráneos bajo ombroclima húmedo. La combinación característica está formada por Juniperus phoenicea, Juniperus oxycedrus y Rhamnus myrtifolius, siendo Abies pinsapo especie característica de la subasociación y Ulex baeticus s. l. y Ononis reuteri especies territoriales. Podemos distinguir una variante mesomediterránea con Pinus halepensis. Es de distribución rondense (sector Rondeño). Constituyen la vegetación climácica de la serie de los sabinares del Rhamno-Junipereto phoeniceae abietetoso $S$.

\section{Paeonio broteroi-Abietetum pinsaponis}

Asensi y Rivas Martínez 1976

juniperetosum phoeniceae Pérez Latorre y Cabezudo subass. nova

[Tabla 3, sintypus inv. $\mathrm{n}^{\circ}$ 5]

Pinsapares con sabinas, edafoxerófilos, sobre dolomías y calizas duras, supramesomediterráneos bajo ombroclima húmedo. Subasociación caracterizada por Juniperus phoenicea y Ononis reuteri. Son comunes en el sotobosque Daphne laureola y Helleborus phoetidus y muy escasas otras especies de Querco-Fagetea. Se reconoce una variante mesomediterránea con Pinus halepensis. Su distribución es rondense (sector Rondeño). Estos pinsapares y su variante constituyen la etapa climácica de la serie del Paeonio-Abieteto pinsaponis juniperetoso phoeniceae $S$.

\section{Pruno mahalebo-Berberidetum hispanicae}

Asensi y Rivas-Martínez 1979

prunetosum postratae Pérez Latorre y

Cabezudo subass. nova.

[Tabla 4, sintypus inv. $n^{\circ} 3$ ]

Espinares caducifolios basófilos, oromediterráneos y supramediterráneos superiores con ombroclima húmedohiperhúmedo, caracterizados y diferenciados de la subasociación típica (berberidetosum) por la presencia de Prunus postrata, Rosa micrantha, Rosa nitidula, Juniperus sabina, Rhamnus saxatilis, Rosa squarrosa, Crataegus granatensis y Geum heterocarpum. Su distribución es Rondense (sector Rondeño). Constituye la orla preforestal y primera etapa de sustitución del Daphno-Pineto sylvestris $S$ y Daphno-Acereto granatensis quercetoso alpestris $S$.

\section{Abieto pinsapo-Juniperetum sabinae Pérez}

Latorre y Cabezudo ass. nova

[Tabla 5 , sintypus inv. $\mathrm{n}^{\circ} 6$ ]

Sabinares y enebrales calcícolas oromediterráneos con ombroclima hiperhúmedo. La combinación característica lleva Juniperus sabina, Juniperus communis y Abies pinsapo, siendo especie diferencial Juniperus phoenicea y destacable la presencia del endemismo Ononis reuteri. Las especies de Querco-Fagetea son frecuentes debido a las abundantes precipitaciones en la zona alta de la Sierra. Su distribución está restringida a las cumbres de las Sierras de Tolox y de las Nieves en el subsector Rondense (sector Rondeño). Constituyen la irradiación más suroccidental de la clase Pino-Juniperetea en la Península Ibérica y etapa climácica de la serie del DaphnoPineto sylvestris abietetoso pinsaponis $S$. 
En Argelia (Quézel y Barbero, 1989) ha sido descrita una alianza (Lonicero kabylicaeJuniperion hemispahericae, QuercoCedretalia atlanticae, Quercetea pubescentis), con dos asociaciones caracterizadas por $J$. communis y J. sabina de las que la descrita por nosotros parece ser vicariante.

Cytiso plumosi-Ulicetum baetici Nieto

Caldera, Pérez Latorre y Cabezudo ass. nova ulicetosum baetici

[Tabla 6, sintypus inv. $\mathrm{n}^{\circ} 5$ ]

Aulagares calcícolas, mesosupramediterráneos bajo ombroclima subhúmedo-húmedo. La combinación característica está formada por los endemismos Ulex baeticus y Cytisus fontanesii subsp. plumosus, acompañados por Helianthemum appeninum subsp. asperum y Phlomis crinita como especies diferenciales. Son frecuentes Phlomis lychnitis, Ptilostemon hispanicus y Thymus mastichina. Su distribución es rondense (sector Rondeño). Nos inclinamos por desechar su inclusión en Lavandulo-Echinospartion boissieri debido a la ausencia de las especies características (Lavandula lanata y Echinospartum boissieri) y a su ecología (calizas en lugar de dolomías). Preferimos incluir esta comunidad en la alianza Micromerio-Coridothymion capitati, estando bien diferenciada del Genisto-Cytisetum fontanesii Rivas Goday y Rivas Martínez 1969. Esta asociación es una etapa serial del PaeonioAbieteto pinsaponis juniperetoso phoeniceae $S$, Rhamno-Junipereto phoeniceae abietetoso $S$ y Paeonio-Querceto rotundifoliae $S$.

erinaceetosum Nieto Caldera, Pérez Latorre y Cabezudo subass. nova.

[Tabla 6 , sintypus inv. $\mathrm{n}^{\circ} 1$ ]

Subasociación que alcanza el horizonte inferior del piso supramediterráneo, tomando las especies porte almohadillado y enriqueciéndose con Erinacea anthyllis. Constituye etapa serial del Daphno-Acereto granatensis aceretoso S, Paeonio-Abieteto pinsaponis juniperetoso $S$, Paeonio-Querceto rotundifoliae $S$ y Rhamno-Junipereto phoeniceae abietetoso $S$.

Lavandulo lanate-Ulicetum baetici Martínez Parras, Peinado y De la Cruz 1987 nom. inv. Asensi y Díez Garretas 1988

salvietosum lavandulifoliae Pérez Latorre y Cabezudo subass. nova.

[sintypus: MA, Parque Natural Sierra de las Nieves. Yunquera. Cañada de la Encina. Or. Norte. Alt. 1250 m. Cob. 50\%. Area 100 $\mathrm{m}^{2}$. Litol. Dolomías arenosas. Características de asociación y subasociación: Lavandula lanata 3, Ptilostemon hispanicus +, Salvia lavandulifolia 2, Ulex baeticus subsp. baeticus 2. Características de unidades superiores: Cistus albidus 4, Echinospartum boissieri +, Rosmarinus officinalis 2. Compañeras: Carlina corymbosa + , Daphne gnidium + , Helianthemum marifolium subsp. marifolium 1, Helichrysum stoechas 1, Juniperus oxycedrus + , Orobanche purpurea + , Pinus halepensis + , Sanguisorba minor +, Scabiosa turolensis subsp. grosii + , Teucrium similatum +, Thymus granatensis +, Thymus mastichina +.]

Aulagares dolomitícolas, mesosupramediterráneos, bajo ombroclima húmedo. Subasociación con Salvia lavandulifolia que marca la presencia de dolomías arenosas y matiza, junto a otros táxones, el subsector Rondense en su parte septentrional. Constituye una etapa serial del Paeonio-Abieteto pinsaponis abietetoso $S$.

\section{Astragalo nevadensis-Bupleuretum spinosi}

Pérez Latorre y Cabezudo ass. nova

[Tabla 7 , sintypus inv. $\mathrm{n}^{\circ}$ 7]

Piornales xeroacánticos calcícolas oro supramediterráneos bajo ombroclima húmedohiperhúmedo. La combinación característica viene dada por Astragalus sempervirens subsp. nevadensis y Bupleurum spinosum siendo diferenciales Veronica fontqueri, Erodium cheilantifolium, Arenaria erinacea y Phlomis 
crinita y característicos los endemismos rondeños Ononis reuteri, Erysimum rondae y Koeleria dasyphylla. Su distribución es rondense (sector Rondeño). Asociación que sustituye en la zona de estudio al FestucoAstragaletum granatensis Quézel 1953. Constituye etapa serial del Daphno-Pineto sylvestris $S$ y del Daphno-Acereto granatensis quercetoso alpestris $S$

\section{Genisto viciosoi-Velletum spinosae Pérez}

Latorre y Cabezudo ass. nova

[Tabla 8, sintypus inv. $\mathrm{n}^{\mathbf{0}} 3$ ]

Piornales xeroacánticos hiperxerófilos dolomitícolas, supra-oromediterráneos y bajo ombroclima húmedo. Las especies características son Genista longipes subsp. viciosoi y Vella spinosa. Son especies territoriales en el sector Rondeño Ulex baeticus subsp. bourgaeanus y Teucrium lerrouxi. Presenta distribución bética (sectores Rondeño, Subbético y Almijarense). Esta asociación es vicariante ecológica de la asociación calcícola caracterizada por Genista longipes subsp. longipes (Talavera, Salgueiro, Sáez y Cabezudo, 1998) de las Sierras Béticas orientales (Erinaceo-Genistetum longipedis Bolós y Rigual in Bolós 1967). Constituye la primera etapa serial del Rhamno-Junipereto phoeniceae abietetoso $S$ e incluso la vegetación permanente en crestas y espolones dolomíticos.

\section{Galio baetici-Thymetum granatensis Mota y} Valle 1992

convolvuletosum boissieri Pérez Latorre y Cabezudo subass. nova

[sintypus: MA, Parque Natural Sierra de las Nieves. Yunquera. Puerto de los Hornillos. Or. Oeste. Alt. 1500 m. Cob. $25 \%$. Area $50 \mathrm{~m}^{2}$. Litol. dolomías arenosas. Características de asociación y subasociación: Arenaria erinacea 1, Convolvulus boissieri 2, Helianthemum marifolium subsp. marifolium + , Jurinea pinnata + , Scabiosa turolensis subsp. grosii + , Sideritis incana subsp. occidentalis + , Thymus granatensis 1. Características de unidades superiores: Asperula aristata subsp. scabra +, Bupleurum spinosum + , Echinospartum boissieri 1, Erinacea anthyllis + , Lithodora fruticosa + , Teucrium similatum + , Ulex baeticus subsp. bourgaeanus + , Vella spinosa + . Compañeras: Carex hallerana + , Koeleria vallesiana subsp. humilis 1, Sanguisorba minor +.]

Esta subasociación está presente en los horizontes superiores del piso supramediterráneo, e incluso en el oromediterráneo por efecto topográfico, sobre dolomías arenosas, donde sustituye a la subasociación típica (thymetosum granatensis), y está marcada por la aparición de Convolvulus boissieri. Presenta su distribución en zonas septentrionales del subsector Rondense (sector Rondeño). Constituye una etapa serial del Rhamno-Junipereto phoeniceae abietetoso pinsaponis $S$.

\section{Seselio granatensis-Festucetum hystricis}

Martínez Parras, Peinado y Alcaraz 1987

arenarietosum erinacei Pérez Latorre y Cabezudo subass. nova

[Tabla 9, sintypus inv. $\left.\mathrm{n}^{\circ} 4\right]$

Pastizal psicroxerófilo, basófilo, orosupramediterráneo y bajo ombroclima húmedohiperhúmedo. Como especies características se encuentran Poa ligulata y Festuca hystrix, siendo notable la ausencia de Seseli granatense. Como especies características de la subasociación destacan Arenaria erinacea y Erodium cheilanthifolium. Esta comunidad es de distribución rondense (sector Rondeño) y almijarense (sector Almijarense, Sierra Tejeda). Debido a características fitogeográficas propias se pueden reconocer dos variantes: una rondeña caracterizada por Koeleria dasyphylla y otra almijarense con Armeria filicaulis. También es posible diferenciar una tercera variante, con $P o a$ bulbosa, en zonas majadeadas. La subasociación típica (festucetosum hystricis) se distribuye por las sierras béticas más orientales.

La subasociación y sus variantes 
constituyen etapas seriales del Daphno-Pineto sylvestris $S$ y Daphno-Acereto granatensis quercetoso alpestris $S \mathrm{y}$, en ocasiones, la vegetación permanente de crestas y litosuelos.

\section{Arenarietum arundanae Pérez Latorre y} Cabezudo ass. nova

[Tabla 10, sintypus inv. $\left.{ }^{\circ} 4\right]$

Pastizal terofítico dolomitícola de fenología primaveral, supra-mesomediterráneo con ombroclima húmedo. Estos pastizales anuales están caracterizados por Arenaria arundana, siendo especie diferencial Chaenorrhinum rubrifolium subsp. rubrifolium, y teniendo como territorial a Viola demetria. Su distribución es rondense (sector Rondeño). Asociación vicariante fitogeográfica del Jasiono-Linarietum saturejoides Rivas Martínez, Izco y Costa 1973, de distribución Mijense y Almijarense. El pastizal, también anual, de Violo-Jonopsidietum prolongoi Asensi, Díez Garretas y Esteve 1979 ocupa posiciones ecológicas distintas (calizas, medios rupícolas) a las de esta nueva asociación. Constituye una etapa serial del PaeonioAbieteto pinsaponis juniperetoso phoeniceae $S$, del Rhamno-Junipereto phoeniceae abietetoso pinsaponis $S$ y del PaeonioQuerceto rotundifoliae $S$.

\section{Centaureo baeticae-Carlinetum corymbosae}

Pérez Latorre y Cabezudo ass. nova

[Tabla 11, sintypus inv. ${ }^{\circ} 2$ ]

Cardales nitrófilos y basófilos, de fenología estival, meso y supramediterráneos con ombroclima subhúmedo-húmedo. La combinación característica vienen dada por Carlina corymbosa y Centaurea pullata subsp. baetica, siendo diferenciales Carduus tenuiflorus, Cirsium echinatum, Eryngium dilatatum y Onopordon illyricum. Su distribución en principio es rondense (sector Rondeño) aunque podrían estar representados en sierras calizas de sectores adyacentes. Constituyen etapas seriales del Daphno-
Acereto granatensis $S$, Daphno-Pineto sylvestris S, Paeonio-Querceto rotundifoliae $S$, Paeonio-Abieteto pinsaponis $S$ y RhamnoJunipereto phoeniceae abietetoso $S$.

Chaenorrhino villosae-Campanuletum mollis Rivas Goday 1953

athamantetosum vayredanae Pérez Latorre y Cabezudo subass. nova

[Tabla 12, sintypus inv. $\mathrm{n}^{\circ} 2$ ]

Subasociación rupícola, basófila, de grietas de rocas umbrías, en los pisos meso y supramediterráneo y bajo ombroclima húmedo. Las especies más frecuentes y características son Athamanta vayredana, Campanula velutina, y Chaenorrhinum villosum, apareciendo a veces Centaurea clementei. Esta subasociación es de distribución rondense y mijense (sector Rondeño). Constituye un sintaxon separado geográficamente y ecológicamente del Athamantetum vayredanae López Guadalupe y Esteve Chueca 1982. Aparece como vegetación rupícola en las series del Pino-Junipereto phoeniceae S, DaphnoAcereto granatensis $S$, Paeonio-Abieteto pinsaponis juniperetoso phoeniceae $S \mathrm{y}$ Rhamno-Junipereto phoeniceae abietetoso $S$.

Sarcocapnetum baeticae Pérez Latorre y Cabezudo ass. nova

[Tabla 13, sintypus inv. $\mathrm{n}^{\circ}$ 2]

Vegetación espeluncícola, ligeramente nitrófila y basófila, que se desarrolla en los pisos meso y supramediterráneo con ombroclima húmedo. La especie característica es Sarcocapnos baetica subsp. baetica que se acompaña de muy pocas especies: Campanula velutina, Galium nevadense, Leontodon taraxacoides, Silene andryalifolia, etc. Es de distribución rondense (sector Rondeño). A esta comunidad habría que referir parte de las especies del Sarcocapno baeticaeCentaureetum clementei Asensi y Esteve 1977, ya que sus especies características ocupan ecotopos distintos (Centaurea clementei grietas 
anchas y heliófila versus Sarcocapnos baetica de grietas pequeñas y umbrófila). Constituye un tipo de vegetación rupícola en el dominio de la serie del Paeonio-Abieteto pinsaponis $S$.

\section{Rhamno pumili-Saxifragetum granatensis}

Pérez Latorre y Cabezudo ass. nova

[Tabla 14, sintypus inv. $\mathrm{n}^{\circ}$ 7] saxifragetosum granatensis

Comunidad rupícola, basófila, (meso) supra - oromediterránea y bajo ombroclima húmedo-hiperhúmedo. Las especies que forman la combinación característica son Saxifraga globulifera, Rhamnus pumilus, Erodium cheilanthifolium y Silene andryalifolia. Se considera como territorial Armeria villosa subsp. villosa. Especies como Asplenium rutamuraria, Centranthus nevadensis, Draba hispanica, Hieracium baeticum, Jasione foliosa, Galium nevadense y Potentilla petrophila nos hacen incluir sin dudas a esta asociación en Potentilletalia caulescentis, y por tanto en la alianza bética Saxifragion camposii. La subasociación típica es de distribución rondense (sector Rondeño). En roquedos orientados al sur, la comunidad se empobrece notablemente y queda caracterizada por Hieracium baeticum, Galium baeticum y Jasione foliosa.

galietosum pulvinati Pérez Latorre y Cabezudo subass. nova

[Tabla 14, sintypus inv. $\mathrm{n}^{\circ} 1$ ]

Subasociación sobre dolomías, cuya especie característica es el endemismo rondeño Galium pulvinatum. Es de distribución rondense y mijense (sector Rondeño).

La asociación constituye un tipo de vegetación rupícola en las series del DaphnoAcereto granatensis S, Daphno-Pineto sylvestris S, Paeonio-Abieteto pinsaponis $S$, Paeonio-Querceto rotundifoliae $S$ y RhamnoJunipereto phoeniceae $S$.

\section{Asplenio billotii-Dianthetum lusitani Pérez}

Latorre y Cabezudo ass. nova
[Tabla 15, sintypus inv. $\left.\mathrm{n}^{\circ} 1\right]$

Vegetación rupícola, silicícola, que se desarrolla en el piso mesomediterráneo bajo ombroclima húmedo. La combinación característica viene dada por Dianthus lusitanus que se acompaña de Asplenium billotii y Digitalis purpurea var. tomentosa. Es de distribución marbellí alcanzando los alcornocales entre Ronda y Grazalema (sector Aljíbico). Se incluye en Rumici-Dianthion lusitani (Rumicetalia indurati) por su ecología y presencia de Dianthus lusitanus. Constituye la irradiación más al sur de la Península Ibérica de esta alianza y un tipo de vegetación rupícola en las series del Teucrio-Querceto suberis $S$ y Cytiso-Querceto pyrenaicae $S$.

Ranunculo macrophylli-Juncetum inflexi Pérez Latorre, Galán de Mera y Cabezudo ass. nova

[Tabla 16, sintypus inv. $\mathrm{n}^{\circ} 5$ ]

Juncales basófilos, de suelos temporalmente hidromorfos y nitrificados, meso y supramediterráneos bajo ombroclima subhúmedohúmedo. Consideramos combinación característica a Ranunculus macrophyllus y Juncus inflexus, como diferenciales a Mentha rotundifolia, Festuca arundinacea subsp. atlantigena, Carex mairii y Potentilla reptans y como territorial a Narcissus bugei. Son de distribución rondense (sector Rondeño) aunque podrían alcanzar territorios adyacentes. La comunidad sobre suelos básicos más cercana sintaxonómicamente es el Cirsio-Juncetum inflexi Vigo 1968. Constituyen etapa serial de las series edafohigrófilas basófilas, como las fresnedas del Ficario-Fraxineto angustifoliae S y aparecen puntualmente sobre suelos arcillosos temporalmente encharcados en el dominio del Daphno-Acereto granatensis aceretoso $\mathrm{S}$.

\section{Elymo repentis-Phalaridetum coerulescentis Pérez}

Latorre, Galán de Mera y Cabezudo ass. nova

[Tabla 17, sintypus inv. $\mathrm{n}^{\circ} 1$ ]

Pastizales vivaces higrófilos, de suelos 
arcillosos con hidromorfía temporal y desarrollo en primavera-verano, mesosupramediterráneos bajo ombroclima húmedo. Las especies que forman la combinación característica son Achillea ageratum, Achillea odorata, Elymus repens, Koeleria vallesiana subsp. humilis y Phleum bertolonii siendo territorial Narcissus bugei. Táxones como Gaudinia fragilis, Leontodon tingitanus, Phalaris caerulescens y Scilla peruviana permiten incluir esta asociación en la alianza Gaudinio-Hordeion bulbosi y el orden Phalaridetalia coerulescentis. Estos pastizales son de distribución rondense (sector Rondeño) aunque podrían aparecer en ecologías similares en territorios adyacentes, e incluso más alejados, como podría ser el caso de la comunidad de Phalaris caerulescens citada por López (1978) en la Serranía de Cuenca. La presencia de algunas de las especies citadas (Achillea odorata, Koeleria vallesiana subsp. humilis, Ononis repens subsp. australis y Phleum bertolonii) podrían relacionar esta asociación con los pastizales submediterráneos europeos de Festuco-Brometea erecti Br.-Bl. \& Tx. 1943 (Rivas Goday y Rivas Martínez 1963, Loidi et al. 1997). Constituyen etapa serial del Ficario-Fraxineto angustifoliae $S$ y pueden aparecer a modo de praderas en la serie del Daphno-Acereto granatensis aceretoso $S$.

\section{Series de vegetación climatófilas}

\section{Alcornocales}

1. Myrto communis-Querceto suberis $S$. Serie iberomarroquí-atlántica, silicícola-sabulícola, termomediterránea, subhúmeda del alcornoque (Quercus suber). Faciación sobre sustratos duros, quercetoso suberis.

La vegetación climácica estaría compuesta por un alcornocal de Myrto-Quercetum suberis y un madroñal de orla del Cytiso-Arbutetum unedi quercetosum cocciferae. Por talas, incendios recurrentes y sobrepastoreo estas formaciones han sido sustituidas en el Parque por diversos tipos de jarales. En el contacto de esquistos y peridotitas podemos observar un matorral de Asperulo-Staehelinetum baetici, mientras que sobre esquistos aparece un jaral con jaguarzo blanco del CalicotomoGenistetum lanuginosae halimietosum atriplicifolii. En zonas occidentales se desarrolla un jaral de Calicotomo-Genistetum lanuginosae típico y en las más orientales encontramos jarales con bolinas del Calicotomo-Genistetum lanuginosae genistetosum umbellatae. Los pastizales anuales son de una comunidad con Tuberaria guttata.

Pastizales: Poo-Trifolietum subterranei y comunidad de Calendula arvensis.

2. Teucrio baetici-Querceto suberis S. Serie aljíbico-tingitana silicícola, mesotermomediterránea, húmeda del alcornoque (Quercus suber). Variante marbellí con pinsapos (Abies pinsapo).

La fase climácica de esta serie la constituyen los alcornocales de TeucrioQuercetum suberis var. de Abies pinsapo, muy bién conservados en algunas zonas del Parque. En el seno de estos bosques se desarrollan madroñales de Cytiso-Arbutetum unedi que puede constituir en las umbrías, formaciones arbóreas. Sobre la capa de humus se desarrolla un pastizal esciohumícola de CalaminthoGalietum scabri. Este alcornocal ha sido sustituido desde hace tiempo en algunas zonas por cultivos de Castanea sativa (castaño). Por talas, incendios recurrentes y sobrepastoreo estas formaciones son sustituidas por diversos tipos de jarales. En zonas térmicas del sur del Parque se desarrolla un jaral de CalicotomoGenistetum lanuginosae típico, en umbrías una variante con Calluna vulgaris, y en las zonas más sudorientales encontramos jarales con bolinas del Calicotomo-Genistetum lanuginosae genistetosum umbellatae. En áreas interiores más frescas se desarrollan jarales 
con Cistus monspeliensis. Los pastizales anuales son de una comunidad con Tuberaria guttata.

Pastizales: Poo-Trifolietum subterranei y comunidad de Calendula arvensis.

Vegetación rupícola: Polypodietum cambrici, Asplenio-Dianthetum lusitani y Selaginello-Anogrammetum leptophyllae.

\section{Encinares}

\section{Paeonio coriaceae-Querceto rotundifoliae}

S. Serie bética, calcícola, mesomediterránea seco-subhúmedo-húmeda de la encina (Quercus rotundifolia). Faciación con quejigos quercetoso fagineae. Variantes rondenses con alcornoques (Quercus suber) y con pinsapos (Abies pinsapo).

La etapa climácica de esta serie está constituída por encinares que en el Parque se presentan bajo tres faciaciones. Sobre calizas y en zonas más llanas aparece el encinar con quejigos del Paeonio-Quercetum rotundifoliae quercetosum fagineae. En las zonas más montanas y sobre dolomías se desarrolla el encinar con pinsapos de Paeonio-Quercetum rotundifoliae quercetosum fagineae var. de Abies pinsapo. Finalmente, sobre suelos descarbonatados o silíceos encontramos el encinar con alcornoques de PaeonioQuercetum rotundifoliae quercetosum fagineae var. de Quercus suber. Estos bosques presentan en el sotobosque pastizales escionitrófilos anuales con Geranium lucidum y herbazales esciohumícolas perennes de ClinopodioOriganetum virentis. Como orla de estos encinares, en las zonas más lluviosas y de suelos más profundos, aparecen espinares caducifolios con Crataegus monogyna, mientras que en zonas rocosas más térmicas y secas la vegetación dominante están constituída por cornicabrales de Pistacia terebinthus. El encinar con alcornoques en zonas térmicas es sustituido por un jaral con Cistus monspeliensis, mientras que en zonas frías, por jarales de Cistus laurifolius. Los encinares con quejigos son sustituidos por matorrales de Cytiso plumosi-Ulicetum baetici mientras que los encinares con pinsapos llevan, como matorral de sustitución, el aulagar de UliciLavanduletum lanatae, pudiendo aparecer en zonas quemadas espartales de Stipa tenacissima y sobre litosuelos dolomíticos tomillares de Galio-Thymetum granatensis y pastizales de Arenarietum arundanae. Si los matorrales se ahuecan se puede instalar un pastizal xerófilo de Phlomido-Brachypodietum retusi. Los pastizales terofíticos generalmente corresponden al Violo-Jonopsidetum prolongoi en suelos oligotrofos.

Pastizales: Medicago-Aegilopetum geniculatae y comunidad de Poa bulbosa.

Vegetación nitrófila: comunidad de Helichrysum serotinum y CentaureoCarlynetum corimbosae.

Vegetación rupícola: ChaenorrhinoCampanuletum mollis, Rhamno-Saxifragetum granatensis, Polypodietum cambrici, Parietarietum lusitanicae y Stachydetum circinatae.

\section{Robledales}

4. Cytiso triflori-Querceto pyrenaicae S. Serie aljíbico-tingitana y rifeña, silicícola, mesomediterránea, húmedo-hiperhúmeda del roble (Quercus pyrenaica). Faciación aljíbica.

La etapa climácica de esta serie no se encuentra en la actualidad en el Parque debido a fuertes transformaciones antrópicas, tan sólo restan algunos indicadores de las etapas maduras de la serie como Quercus pyrenaica, Paeonia broteri, Viola sp., Crataegus monogyna, Pteridium aquilinum y especies aisladas del pastizal esciohumícola del Calamintho-Galietum scabri. En las zonas recientemente incendiadas y sobrepastoreadas encontramos aulagares con Polygala baetica y Ulex baeticus.

Vegetación nitrófila: comunidad de 
Helichrysum serotinum.

Pastizales: Poo-Trifolietum subterranei y comunidad de Holcus lanatus.

Vegetación rupícola: AsplenioDianthetum lusitani y Polypodietum serrati.

\section{Quejigales}

\section{Daphno latifoliae-Acereto granatensis $\mathrm{S}$.} Serie bética, calcícola, supramesomediterránea, subhúmeda-húmeda del quejigo (Quercus faginea). Faciación típica aceretoso granatensis. Faciación rondense quercetoso alpestris.

La faciación típica (aceretoso granatensis) se desarrolla al oeste del Parque y ocupa las zonas mesomediterráneas superiores y supramediterráneas inferiores con ombroclima húmedo. La faciación quercetoso alpestris constituye el llamado "Quejigal de Tolox”, entre los pisos supramediterráneo superior y oromediterráneo inferior, con ombroclima hiperhúmedo.

\section{Faciación aceretoso granatensis}

Debido a la gran deforestación y sobrepastoreo no es posible hallar retazos de la comunidad climácica de esta serie en el Parque, tan sólo se encuentran indicadores como Quercus faginea, Acer monspessulanum, Daphne laureola, Helleborus foetidus y Paeonia spp. La orla natural de estos bosques es un espinar caducifolio que, debido a lo anteriormente expuesto, está muy desdibujado. Generalmente corresponde a espinares de Crataegus monogyna que aparece en contacto con espinares poco desarrollados del PrunoBerberidetum hispanicae. La primera etapa serial, sobre calizas, es un aulagar con bolinas de Cytiso plumosi-Ulicetum baetici típico y erinaceetosum en el piso supramediterráneo. Sobre dolomías, se desarrolla un matorral de Ulici-Lavanduletum lanatae, acompañado sobre litosuelos y áreas desbrozadas por un tomillar de Galio-Thymetum granatensis y pastizales de Arenarietum arundanae. Por degradación (incendios, rozas, etc.), el aulagar de Cytiso plumosi-Ulicetum baetici se transforma en un pastizal subnitrófilo de Medicago-Aegilopetum geniculatae.

Pastizales: comunidad de Poa bulbosa.

Vegetación nitrófila: comunidad de Helichrysum stoechas y Centaureo-Carlinetum corymbosae.

Vegetación rupícola: RhamnoSaxifragetum granatensis y Stachydetum circinatae.

Vegetación hidrófila: ElymoPhalaridetum coerulescentis.

2. Faciación quercetoso alpestris.

Se trata de la formación de quejigos a mayor altitud de la Península Ibérica, instalada en el límite entre los pisos supra y oromediterráneo, con ombroclima hiperhúmedo y sobre calizas. El uso (carboneo, pastoreo, neveros) al que esta comunidad ha estado sometida por el hombre ha dado lugar a una dehesa de Quercus alpestris con céspedes de Poa bulbosa.

La vegetación climácica debió de estar constituida por bosquetes caducifolios de Daphno-Aceretum granatensis quercetosum alpestris, hoy día sólo reconocibles en áreas valladas al ganado o inaccesibles al mismo, y en el interior de grandes espinares. La orla espinosa caducifolia corresponde al PrunoBerberidetum hispanicae prunetosum postratae. Por efecto topográfico, en los espolones rocosos el espinar es sustituído por un sabinar-enebral orófilo del AbietoJuniperetum sabinae. Al desaparecer la vegetación forestal arbórea y arbustiva y perderse el suelo, se instala un piornal xeroacántico de Astragalo-Bupleuretum spinosi que junto a la comunidad herbácea psicroxerófila de Seselido-Festucetum hystricis arenarietosum erinacei pueden constituir la vegetación permanente de crestas, espolones y áreas venteadas, la cual es sustituida por el tomillar de Galio-Thymetum granatensis y el pastizal de Arenarietum arundanae sobre las 
escasas dolomías presentes a estas altitudes. Sobre suelos calizo-arcillosos y ligeramente nitrificados se instala el pastizal anual de la comunidad de Acinos rotundifolius y Linaria haenseleri, mientras que en medios glerícolas y litosuelos pedregosos se desarrolla el VioloJonopsidietum.

Pastizales: comunidad de Poa bulbosa y variante de Trifolium nevadensis.

Vegetación nitrófila: comunidad de Helichrysum serotinum y CentaureoCarlinetum corimbosae.

Vegetación rupícola: RhamnoSaxifragetum granatensis, Stachydetum circinatae, Sarcocapno-Centaureetum clementei, Chaenorrhino-Campanuletum athamantetosum vayredanae y comunidad de Cystopteris fragilis.

Vegetación hidrófila: comunidad de Trifolium repens.

\section{Sabinares-enebrales orófilos}

6. Daphno oleoidis-Pineto sylvestris S. Serie bética, calcícola, oromediterránea subhúmedohúmeda de la sabina (Juniperus sabina). Faciación rondense abietetoso pinsaponis.

Esta faciación está restringida a las zonas culminales oromediterráneas de la Sierra de las Nieves y de la Sierra de Tolox y a zonas topográficamente desfavorables para el quejigal de Daphno-Aceretum (crestas, espolones, lapiaces, roquedos) en el límite del piso supramediterráneo superior. La vegetación climácica es un sabinar - enebral del AbietoJuniperetum sabinae. Esta formación se encuentra orlada, cuando el suelo es relativamente profundo, por un espinar caducifolio de Pruno-Berberidetum hispanicae prunetosum postratae. A causa de los incendios, talas y pastoreo, que llevan consigo la pérdida de suelo por erosión, se instala el piornal xeroacántico del AstragaloBupleuretum spinosi. En las crestas más venteadas y pavimentos rocosos encontramos como comunidad prácticamente permanente al Seselido-Festucetum arenarietosum erinacei. Cuando el piornal desaparece, y sobre suelos pedregosos, se desarrolla el pastizal de VioloJonopsidietum, apareciendo sobre gleras y canchales otros pastizales perennes con Leucanthemon arundanum y Silene boryi. En suelos más arcillosos aparece el pastizal de Acinos rotundifolius y Linaria haenseleri.

Pastizales: comunidad de Poa bulbosa.

Vegetación nitrófila: comunidad de Helichrysum serotinum y CentaureoCarlinetum corymbosae

Vegetación rupícola: RhamnoSaxifragetum granatensis var. de Hieracium baeticum y comunidad de Cystopteris fragilis.

\section{Series de vegetación edafoxerófilas}

\section{Bunio macucae-Abieteto pinsaponis $S$. Serie} bermejense, serpentinícola, mesosupramediterránea húmeda del pinsapo (Abies pinsapo).

Pinsapares con extensión reducida a debido a los incendios. La fase climácica de esta serie la constituyen los pinsapares de Bunio-Abietetum pinsaponis. En el interior del bosque se desarrollan comunidades umbrófilas y rupícolas ya que, normalmente, el pinsapar se instala en laderas rocosas de gran pendiente. El pastizal de bosque es de tipo escionitrófilo anual con Geranium purpureum. En zonas más húmedas de vaguada y suelos algo menos superficiales aparecen agrupaciones de Rosa carioti. En las grietas umbrosas y terrosas de las rocas aparece la comunidad del AsplenioSaxifragetum gemmulosae. Al desaparecer el pinsapar es sustituido por un jaguarzal de GalioStahelinetum baetici. Gracias a su temperamento xerófilo, Pinus pinaster y especies del Pino-Quercetum cocciferae pueden ocupar antiguas áreas de pinsapar. Entre dicho matorral y las fases aclaradas del pinar paraclimácico aparecen pastizales vivaces del Phlomido-Brachypodietum retusi. Sobre 
litosuelos arenosos el pastizal anual corresponde al Arenario-Iberidetum fontqueri.

Vegetación rupícola: comunidad de Armeria colorata y comunidad de Armeria carratracensis.

\section{Paeonio broteroi-Abietetum pinsaponis $S$.}

Serie Rondense basófila, supramesomediterránea húmeda-hiperhúmeda. Faciación sobre calizas abietetoso pinsaponis. Faciación sobre dolomías juniperetoso phoeniceae.

Existen dos variantes de estos pinsapares. La típica (abietetoso) se desarrolla sobre calizas y en la actualidad se encuentra en fases de matorral (Rosmarinetalia) y pastizales (Taeniathero-Aegylopion), apareciendo en contadas localidades en su fase boscosa. La faciación juniperetoso phoeniceae se desarrolla sobre dolomías y es la más extendida en el Parque, estando óptimamente estructurada y siendo típicos los sabinares (Pino-Juniperion phoeniceae), aulagares (LavanduloEchinospartion) y tomillares (Andryalion agardhii).

\section{Faciación abietetoso pinsaponis.}

La vegetación climácica se corresponde con un pinsapar de Paeonio-Abietetum pinsaponis que lleva en su interior un pastizal escionitrófilo con Geranium lucidum. En la base de cantiles umbríos todavía se puede encontrar una variante con tejos (Taxus baccata). Como orla del pinsapar, y a veces en su interior si se ahueca, encontramos, en el piso mesomediterráneo, el espinar caducifolio de Crataegus monogyna mientras que en el supramediterráneo el espinar es de PrunoBerberidetum hispanicae. Los matorrales de degradación más comunes en esta serie corresponden al aulagar de Cytiso-Ulicetum baetici que, si son aclarados, presentan pastizales vivaces del PhlomidoBrachypodietum en su interior. En zonas medias, sobre suelos descarbonatados, aparece de forma muy puntual el jaral de Cistus laurifolius. Por otro lado y debido a incendios y desbroces, se desarrollan pastizales de dos tipos: sobre suelos rocosos el pastizal es de Violo-Jonopsidietum, mientras que sobre suelos arcillosos algo nitrificados se desarrolla el Medicago-Aegilopetum geniculatae

Pastizales: comunidad de Poa bulbosa.

Vegetación nitrófila: comunidad de Helichrysum serotinum y CentaureoCarlinetum corymbosae

Vegetación rupícola: ChaenorrhinoCampanuletum, Rhamno-Saxifragetum granatensis, Parietarietum judaicae, Sarcocapno-Centaureetum clementei, Chaenorrhino-Campanuletum atamanthetosum y Stachydetum circinatae.

2. Faciación juniperetosum phoeniceae.

La vegetación climácica se corresponde con un pinsapar de Paeonio-Abietetum pinsaponis juniperetosum phoeniceae, que lleva en su interior un pastizal escionitrófilo con Geranium lucidum. Como orla del pinsapar encontramos un sabinar con pinsapos de Rhamno-Juniperetum phoeniceae abietetosum pinsapo. A causa de los incendios el pinsapar es sustituido por matorrales de UliciLavanduletum lanatae típico que puntualmente aparece como subasociación salvietosum lavandulifoliae sobre dolomías arenosas o como subasociación erinaceetosum en el piso supramediterráneo, a veces con Ononis reuteri a modo de orla del pinsapar. En zonas de matorral poco denso aparecen pastizales vivaces del Phlomido-Brachypodietum. Sobre dolomías arenosas y suelos pedregosos se desarrolla un tomillar de Galio-Thymetum granatensis. Sobre suelos arenosos el pastizal es de Arenarietum arundanae, mientras que sobre suelos arcillosos y ligeramente nitrificados se desarrolla el MedicagoAegilopetum geniculatae.

Vegetación nitrófila: comunidad de Helichrysum serotinum y CentaureoCarlinetum corymbosae.

Vegetación rupícola: Chaenorrhino- 
Campanuletum, Rhamno-Saxifragetum granatensis galietosum pulvinati, Parietarietum judaicae, Sarcocapnetum baeticae y Stachydetum circinatae.

\section{Rhamno myrtifoliae-Junipereto phoeniceae}

$S$. Serie bética, calcícola-dolomitícola, mesosupramediterránea, seco-subhúmeda-húmeda de la sabina mora (Juniperus phoenicea). Faciación rondense abietetoso pinsaponis.

La vegetación climácica de esta serie corresponde a sabinares con pinsapos del Rhamno-Juniperetum phoeniceae abietetosum, instalados en espolones, crestas, litosuelos y laderas rocosas muy expuestas. Los matorrales seriales sobre calizas pertenecen al CytisoUlicetum baetici, que aparece a veces junto a espartales de Stipa tenacissima. Sobre dolomías, en el supramediterráneo, aparece el aulagar de Ulici-Lavanduletum lanatae erinaceetosum y también sobre dolomías, pero en zonas térmicas, un matorral de CistoUlicetum baetici, Los tomillares sobre dolomías son de Galio-Thymetum granatensis y los pastizales de derrubios corresponden al Linario-Andryaletum ramosissimae. En áreas supramediterráneas y oromediterráneas por efecto topográfico (divisoria de aguas, crestas, picos) y sobre dolomías, el sabinar deja paso al piornal hiperxerófilo del Genisto viciosoiVelletum spinosae, con tomillares pulvinulares de Galio-Thymetum convolvuletosum boissieri. Los pastizales anuales sobre calizas corresponden al Violo-Jonopsidietum prolongoi mientras que sobre dolomías son del Arenarietum arundanae. Estos pastizales pueden transformarse por el pastoreo en el herbazal subnitrófilo de MedicagoAegylopetum geniculatae.

Pastizales: comunidad de Poa bulbosa.

Vegetación nitrófila: comunidad de Helichrysum serotinum y CentaureoCarlinetum corymbosae

Vegetación rupícola: ChaenorrhinoCampanuletum mollis, Rhamno-Saxifragetum granatensis, Sarcocapno-Centaureetum clementei, Chaenorrhino-Campanuletum mollis athamantetosum, Stachydetum circinatae y Selaginello-Anogrammetum leptophyllae.

\section{Pino halepensis-Junipereto phoeniceae}

S. Serie rondeña, dolomitícola, termomediterránea, subhúmeda-húmeda de la sabina mora (Juniperus phoenicea).

La vegetación potencial está constituída por sabinares con Pinus halepensis y Ceratonia siliqua pertenecientes al Pino-Juniperetum phoeniceae. Por degradación, se instala un matorral xerófilo de Cisto-Ulicetum baetici. En zonas de suelos arenosos la vegetación, de tipo herbáceo vivaz, es de la asociación LinarioAndryaletum ramossisimae. Por degradación del matorral aparece un espartal de la comunidad de Stipa tenacissima. En los litosuelos aparecen pastizales de Arenarietum arundanae o de tipo subnitrófilo del MedicagoAegilopetum geniculatae.

Vegetación nitrófila: comunidad de Helichrysum stoechas.

Vegetación rupícola: SelaginelloAnogrammetum, Sarcocapnetum baeticae, Polypodietum serrulati, ChaenorrhinoCampanuletum mollis, ChaenorrhinoCampanuletum mollis atamanthetosum y Stachydetum circinatae.

\section{Pino pinastri-Querceto cocciferae $\mathrm{S}$. Serie} bermejense, serpentinícola, termomesomediterránea subhúmeda-húmeda del pino negral (Pinus pinaster).

La vegetación climácica en el dominio de esta serie son pinares de pino negral y coscojas pertenecientes al Pino-Quercetum cocciferae. Por aclarado del pinar, aparece una fase con sotobosque de pastizal xerófilo de PhlomidoBrachypodietum. Por degradación de la vegetación arbóreo-arbustiva toma preponderancia el matorral de GalioStaehelinetum baetici, sobre todo en zonas 
rocosas y de fuertes pendientes. En los claros del matorral es frecuente el pastizal terofítico de Arenario-Iberidetum fontqueri o pastizales subnitrófilos de Medicago-Aegilopetum geniculatae. Si el pinar o el matorral se incendian de modo recurrente se desarrolla un jaral con jaguarzos de Calicotomo-Genistetum lanuginosae halimietosum serpentinicolae con un pastizal correspondiente a la comunidad de Tuberaria guttata.

Pastizales: Poo-Trifolietum subterranei

Vegetación rupícola: NotholaenoCheilanthetum guanchicae y Polypodietum cambrici.

\section{Series de vegetación edafohigrófilas}

12. Ficario ranunculoidis-Fraxineto angustifoliae $S$. Serie ibérica del fresno (Fraxinus angustifolia). Variante rondense con Lonicera etrusca.

Las fresnedas debido a la deforestación de la zona oeste del Parque hoy sólo son medianamente reconocibles. La vegetación climácica corresponde a una fresneda del Ficario-Fraxinetum angustifoliae en su variante supramediterránea con Lonicera etrusca y con una orla muy desarrollada de la comunidad Crataegus monogyna. Si se tala la fresneda y/o el espinar se desarrollan juncales de Scirpus holoschoenus en los bordes de los arroyos, del Cirsio-Holoschoenetum exclusivamente en algunas fuentes al norte del Parque y del Ranunculo-Juncetum inflexi en suelos encharcados nitrificados. Sobre suelos arcillosos encharcados se desarrollan praderas hidrófilas de Elymo-Phalaridetum coerulescentis que, en el estío, dejan paso a céspedes subnitrófilos de MedicagoAegilopetum geniculatae. Sumergida en los cauces, aparece la vegetación algal del Charetum vulgaris.

Pastizales: comunidad de Poa bulbosa.

Vegetación nitrófila: CentaureoCarlinetum corymbosae.
13. Equiseto telmateiae-Saliceto pedicellate S. Serie aljíbica y bética del sauce pedicelado (Salix pedicellata). Faciación freatófila nerietoso oleandri.

La vegetación climácica de los ríos y arroyos de aguas permanentes, aunque con fuerte estiaje, sobre calizas y esquistos corresponde en el Parque a saucedas con adelfas de la asociación Equiseto-Salicetum pedicellatae nerietosum oleandri. Se sitúan en los bordes del lecho menor de los ríos y arroyos. Estas formaciones arbustivas o subarbóreas, están orladas por un zarzal del RuboCoryaretum myrtifoliae. Si estas comunidades son desbrozadas o taladas se desarrollan juncales con Scirpus holoschoenus sobre calizas y esquistos, mientras que en contacto directo con el agua y sobre peridotitas se desarrollan herbazales-juncales higrófilos de Galio-Schoenetum molinietosum. Cuando las aguas se nitrifican aparece un herbazal helofítico de Apietum nodiflori.

Vegetación rupícola: SelaginelloAnogrammetum leptophyllae

Vegetación hidrófila: TrachelioAdiantetum.

14. Rubo ulmifolii-Nerieto oleandri S. Serie ibérica de la adelfa (Nerium oleander).

La vegetación climácica termófila de los torrentes y arroyos con fuerte estiaje, sobre esquistos y calizas, corresponde a adelfares de la asociación Rubo ulmifolii-Nerietum oleandri. En lugares angostos y rezumantes aparece una variante con Laurus nobilis. Por degradación aparecen los juncales de Scirpus holoschoenus.

Vegetación rupícola: SelaginelloAnogrammetum leptophyllae

Vegetación hidrófila: Trachelio-Adiantetum.

15. Erico terminalis-Saliceto pedicellatae $\mathrm{S}$. Serie bética del sauce pedicelado (Salix pedicelata). Variante bermejense con Galium viridiflorum. 
La vegetación climácica en los ríos y arroyos de aguas permanentes sobre peridotitas, aunque con fuerte estiaje, corresponde a saucedas con brezos de la asociación EricoSalicetum pedicellatae var. de Galium viridiflorum. Estas formaciones arbustivas están orladas por un zarzal del RuboCoryaretum myrtifoliae. Por degradación se desarrollan los juncales del Galio-Schoenetum nigricantis típico que, siempre en contacto directo con el agua, aparece como subasociación molinietosum caeruleae.

Vegetación hidrófila:Trachelio-Adiantetum.

16. Erico terminalis-Nerieto oleandri galietoso viridiflori $\mathbf{S}$. Serie bermejense de la adelfa (Nerium oleander).

La vegetación climácica sobre peridotitas en los ríos y arroyos, sobre sustrato peridotítico y de aguas estacionales, corresponde a adelfares con brezos de la asociación Erico-Nerietum oleandri galietosum viridiflori. Por degradación se desarrollan los juncales de Galio-Schoenetum nigricantis en arroyos de aguas permanentes o juncales de Scirpus holoschoenus en una variante con Galium viridiflorum en arroyos con fuerte estiaje.

Vegetación rupícola: SelaginelloAnogrammetum leptophyllae.

\section{ESQUEMA SINTAXONÓMICO}

I. Vegetación potencial y orlas arbustivas siempreverdes y aciculifolias

\section{QUERCETEA ILICIS Br.-B1. 1947}

+ Quercetalia ilicis Br.-B1. ex Molinier 1934 em. Rivas-Martínez 1975

* Quercion broteroi (fagineae) Br.-B1., P. Silva y Rozeira 1956 corr. Ladero 1974 em. RivasMartínez 1975

** Paeonio broteroi-Quercenion rotundifoliae Rivas-Martínez in Rivas-Martínez, Costa e Izco 1986
1. Paeonio coriaceae-Quercetum rotundifoliae quercetosum fagineae RivasMartínez 1964 em. Rivas Goday y RivasMartínez 1971. [Encinares con quejigos].

var. de Abies pinsapo. [Encinares con pinsapos].

var. de Quercus suber. [Encinares con alcornoques].

* Quercion suberis Loisel 1971

2. Teucrio baetici-Quercetum suberis Rivas-Martínez ex Díez Garretas, Cuenca y Asensi 1988.

quercetosum suberis. [Alcornocales ombrófilos].

var. de Pistacia lentiscus. [Variante termófila].

var. de Abies pinsapo. [Alcornocales con pinsapos].

3. Com. de Castanea sativa. [Castañares paraclimácicos].

4. Myrto communis-Quercetum suberis Barbero, Quézel y Rivas-Martínez 1981. [Alcornocales termófilos].

+Pistacio lentisci-Rhamnetalia alaterni RivasMartínez 1975

* Pino pinastri-Juniperion phoeniceae Pérez Latorre y Cabezudo all. nova [Vegetación edafoxerófila magnesícola con gimnospermas ].

\section{** Pino-Junipereneion}

5. Pino pinastri-Quercetum cocciferae Cabezudo, Nieto Caldera y Pérez Latorre 1989. [Pinares-coscojares serpentinícolas].

6. Pino halepensis-Juniperetum phoeniceae Pérez Latorre y Cabezudo ass. nova. [Sabinares con pinos carrascos, edafoxerófilos, termomediterráneos, rondeños].

\section{juniperetosum phoeniceae}

genistetosum haenseleri comb. nova. [Variante mijense].

7. Rhamno myrtifoli-Juniperetum phoeniceae Molero Mesa y Pérez Raya 1987. abietetosum pinsaponis Pérez Latorre y Cabezudo subass. nova [Sabinares con 
pinsapos, edafoxerófilos, mesosupramediterráneos, rondeños].

* Paeonio-Abietenion pinsapo RivasMartínez 1987

8. Paeonio broteroi-Abietetum pinsaponis Asensi y Rivas-Martínez 1976. [Pinsapares calcícolas].

\section{abietetosum pinsaponis}

var. de Taxus baccata. [Pinsapares con tejos].

juniperetosum phoeniceae Pérez Latorre

y Cabezudo subass. nova [Pinsapares edafoxerófilos con sabinas].

9. Bunio macucae-Abietetum pinsaponis (Asensi y Rivas-Martínez 1976) RivasMartínez 1987. [Pinsapares serpentinícolas].

* Rhamno-Quercion cocciferae Rivas Goday ex Rivas-Martínez 1975

10. Com. de Pistacia terebinthus. [Cornicabrales].

* Ericion arboreae Rivas-Martínez (1975) 1987

11. Cytiso baetici-Arbutetum unedonis Nieto Caldera, Pérez Latorre y Cabezudo 1990. [Madroñales aljíbicos con escobones].

II. Vegetación potencial caducifolia y aciculifolia y sus orlas arbustivas. vegetación riparia.

QUERCO-FAGETEA Br.-Bl. \& Vlieger in Vlieger 1937

+Quercetalia pubescenti-petraeae Klika 1933

* Aceri granatensis-Quercion fagineae (Rivas Goday, Rigual y Rivas-Martínez in Rivas Goday et al. 1960) Rivas-Martínez 1987

** Aceri granatensis-Quercenion fagineae (Rivas Goday, Rigual y Rivas-Martínez in RivasMartínez et al. 1960) Rivas-Martínez 1987

12. Daphno latifoliae-Aceretum granatensis Rivas Martínez 1964

aceretosum granatensis

quercetosum alpestris Nieto Caldera, Pérez Latorre y Cabezudo 1991. [Quejigales supramediterráneos con arces y serbales].

* Quercion robori-pyrenaicae (Br.-B1., P.
Silva, Rozeira \& Fontes 1950) Rivas-Martínez 1975

** Quercenion pyrenaicae Rivas-Martínez 1975

13. Cytiso triflori-Quercetum pyrenaicae Barbero, Quézel \& Rivas-Martínez 1981. [Robledales ombrófilos].

+ Populetalia albae Br.-Bl. ex Tchou 1948

* Populion albae Br.-B1. ex Tchou 1948

** Fraxino-Ulmenion minoris Rivas-Martínez 1975

14. Ficario ranunculoides-Fraxinetum angustifoliae Rivas-Martínez y Costa in RivasMartínez, Costa, Castroviejo y Valdés 1980.

var. de Lonicera etrusca. [Fresnedas supramediterráneas].

+ Salicetalia purpureae Moor 1958

* Salicion salvifoliae Rivas-Martínez, T.E. Díaz, Prieto, Loidi y Penas 1984

15. Equiseto telmateiae-Salicetum pedicellatae nerietosum oleandri Díez Garretas, Cuenca y Asensi 1988. [Saucedas con adelfas].

16. Erico mediterraneae-Salicetum pedicellatae Esteve 1973

var. de Galium viridiflorum. [Saucedas serpentinícolas con brezos].

+ Prunetalia spinosae Tüxen 1952

* Pruno-Rubion ulmifolii O. Bolós 1954

** Pruno-Rubenion ulmifolii

17. Rubo ulmifolii-Coriarietum myrtifoliae O. Bolós 1954. [Zarzales con garapalo].

** Rosenion carioto-pouzinii Arnaiz 1979

18. Com. de Crataegus monogyna. [Espinares caducifolios con majuelos y rosales].

* Lonicero arboreae-Berberidion hispanicae O. Bolós 1954

19. Pruno mahalebo-Berberidetum hispanicae Asensi y Rivas-Martínez 1979.

berberidetosum hispanicae. [Espinares caducifolios con agracejos y durillos].

prunetosum postratae Pérez Latorre y Cabezudo subass. nova. [Variante orófila]. 
PINO-JUNIPERETEA Rivas-Martínez 1964

+ Pino-Juniperetalia Rivas-Martínez 1964

* Pino-Juniperion sabinae Rivas Goday in Rivas Goday y Borja 1961

20. Abieto pinsapo-Juniperetum sabinae Pérez Latorre y Cabezudo ass. nova. [Sabinares y enebrales oromediteráneos rondeños].

NERIO-TAMARICETEA Br.-Bl. y O. Bolós 1958

* Rubo ulmifolii-Nerion oleandri O. Bolós 1985

21. Rubo ulmifolii-Nerietum oleandri $\mathrm{O}$. Bolós 1956. [Adelfares].

var. de Laurus nobilis. [Adelfares con laurel].

22. Erico-Nerietum oleandri galietosum viridiflori Rivas Goday y Esteve 1972. [Adelfares serpentinícolas].

III. Matorrales y orlas herbáceas

CISTO-LAVANDULETEA Br.-Bl. (1940) 1952 + Lavanduletalia stoechidis Br.-B1. 1940 em. Rivas-Martínez 1968

* Ulici argentei-Cistion ladaniferi (Br.-Bl. 1940) Br.-B1., Silva \& Rozeira 1964 em. RivasMartínez 1979

** Ulici-Calicotomenion villosae Pérez Latorre, Navas, Cabezudo y Nieto Caldera 1997

23. Calicotomo villosae-Genistetum lanuginosae Martínez Parras, Peinado y De la Cruz 1987 corr. Pérez Latorre, Galán de Mera, Deil y Cabezudo 1996. [Jarales con jérguenes].

genistetosum lanuginosae

var. de Calluna vulgaris. [Jarales con brecinas].

halimietosum serpentinicolae Asensi y Díez (1988) 1991. [Jarales serpentinícolas con jaguarzos blancos].

genistetosum umbellatae Martínez Parras, Peinado y de la Cruz 1987. [Jarales con bolinas].

24. Com. de Cistus monspeliensis. [Jarales de interior].

* Cistion laurifolii Rivas Goday in Rivas Goday et al. 1956 em. Rivas-Martínez 1979

25. Com. de Cistus laurifolius [Jarales de jara estepa].

26. Com. de Ulex baeticus y Polygala baetica. [Aulagares silicícolas mesomediterráneos].

* Staehelino-Ulicion baetici Rivas Goday y Rivas-Martínez 1969

27. Galio boissierani-Staehelinetum baetici Rivas Goday y Rivas-Martínez 1968. [Jaguarzales serpentinícolas].

ROSMARINETEA OFFICINALIS RivasMartínez, T.E. Díaz, F. Prieto, Loidi y Penas 1991

+ Rosmarinetalia Br.-B1. 1931

* Micromerio micranthae-Coridothymion capitati Rivas-Goday y Rivas-Martínez 1969

28. Cisto clusii-Ulicetum baetici Nieto, Pérez Sanz y Cabezudo 1987. [Aulagares dolomitícolas termomediterráneos].

29. Cytiso plumosi-Ulicetum baetici Nieto, Pérez Latorre y Cabezudo ass. nova. [Aulagares calcícolas mesosupramediterráneos].

ulicetosum baetici

erinaceetosum Nieto, Pérez Latorre y Cabezudo subass. nova [Variante supramediterránea].

* Lavandulo lanatae-Echinospartion (Genistion) boissieri Rivas Goday y RivasMartínez 1969

30. Lavandulo lanate-Ulicetum baetici Martínez Parras, Peinado y De la Cruz 1987 nom. inv. Asensi y Díez Garretas 1988. [Aulagares con espliego].

ulicetosum baetici

erinaceetosum Martínez Parras, Peinado y De la Cruz 1987. [Aulagar supramediterráneo con piornos].

var. de Ononis reuteri. [Variante con melosas].

salvietosum lavandulifoliae Pérez Latorre y Cabezudo subass. nova [Variante de dolomías arenosas rondeña septentrional]. 
+ Erinacetalia anthyllidis Quézel 1951

* Xeroacantho-Erinaceion (Quézel 1953) O. Bolós 1967

31. Astragalo nevadensis-Bupleuretum spinosi Pérez Latorre y Cabezudo ass. nova. [Matorral xeroacántico de alta montaña caliza rondeña].

32. Genisto viciosoi-Velletum spinosae Pérez Latorre y Cabezudo ass. nova. [Matorral xeroacántico hiperxerófilo de alta montaña dolomítica bética].

+ Convolvuletalia boissieri Rivas-Martínez, Pérez Raya y Molero Mesa in Pérez Raya 1987 * Andryalion agardhii Rivas-Martínez ex Rivas Goday y Mayor 1966

33. Galio baetici-Thymetum granatensis Mota y Valle 1992. [Tomillar de dolomías].

thymetosum granatensis

convolvuletosum boissieri Pérez Latorre

y Cabezudo subass. nova [Variante supramediterránea superior].

IV. Vegetación de pastizales y prados

TRIFOLIO-GERANIETEA SANGUINEI (Th. Müller 1961) Rivas-Martínez y Cantó 1987

+ Origanetalia vulgaris Th. Müller 1961 (1962)

* Origanion virentis Rivas-Martínez y O. Bolós in Rivas-Martínez y col. 1984

34. Clinopodio villosae-Origanetum virentis Rivas-Martínez in Rivas-Martínez et al. 1984.

var. de Teucrium afrum. [Pastizal humícola de lindero de encinares].

35. Calamintho sylvatici-Galietum scabri Pérez Latorre, Nieto y Cabezudo 1993. [Pastizal humícola de lindero de alcornocales].

FESTUCO HYSTRICIS-ONONIDETEA STRIATAE Rivas-Martínez, Prieto, Loidi y Penas 1991

+ Festuco hystricis-Poetalia ligulatae Rivas Goday y Rivas-Martínez 1963

* Minuartio-Poion ligulatae O. Bolòs 1962

36. Seselio granatensis-Festucetum hystricis Martínez Parras, Peinado y Alcaraz 1985

arenarietosum erinacei Pérez Latorre y Cabezudo subass. nova [Pastizal psicroxerófilo vivaz].

var. de Koeleria dasyphylla. [Variante rondeña].

var. de Poa bulbosa. [Variante majadeada].

HELIANTHEMETEA ANNUAE (Br.-Bl. in Br.Bl. \& col. 1952) Rivas Goday y Rivas-Martínez 1963 em. Rivas-Martínez 1978

+ Helianthemetalia guttati Br.-B1. 1940 em. Rivas-Martínez 1978

* Helianthemion guttati Br.-B1. 1931

37. Com. de Tuberaria guttata. [Pastizal terofítico silicícola].

+ Trachynietalia distachyae Rivas-Martínez 1978

* Trachynion distachyae Rivas-Martínez 1978

38. Com. de Acinos rotundifolius y Linaria haenseleri. [Pastizal terofítico supraoromediterráneo].

* Omphalodion commutatae Rivas-Martínez, Izco y Costa in Izco 1975 corr. Pérez Raya 1987

** Omphalodenion commutatae

39. Arenario capillipes-Iberidetum fontqueri Rivas-Martínez, Izco y Costa 1973. [Pastizal terofítico serpentinícola].

** Silenenion germanicae Pérez Raya 1987

40. Arenarietum arundanae Pérez Latorre y Cabezudo ass. nova. [Pastizal terofítico dolomitícola rondense].

41. Violo demetriae-Jonopsidietum prolongoi Asensi, Díez Garretas y Esteve 1979. [Pastizal terofítico calcícola mesosupramediterráneo].

LYGEO SPARTI-STIPETEA TENACISSIMAE Rivas-Martínez 1978

+ Lygeo sparti-Stipetalia tenacissimae $\mathrm{Br}-\mathrm{Bl}$. \& O. Bolós 1958 em. Rivas-Martínez 1978

* Stipion tenacissimae Rivas-Martínez 1978 
42. Com. de Stipa tenacissima. [Espartales].

* Thero-Brachypodion Br.-B1. 1925

43. Phlomido lychnitidisBrachypodietum ramosi (retusi) Br.-B1. 1924. [Pastizales vivaces xerófilos].

POETEA BULBOSAE Rivas Goday y RivasMartínez in Rivas-Martínez 1978

+ Poetalia bulbosae Rivas Goday y RivasMartínez in Rivas Goday y Ladero 1970

* Poo bulbosae-Astragalion sesamei Rivas Goday y Ladero 1970

44. Com. de Poa bulbosa. [Majadales calcícolas].

var. de Trifolium nevadense. [Variante orófila].

*Periballio-Trifolion subterranei Rivas Goday 1964

45. Poo bulbosae-Trifolietum subterranei Rivas Goday 1964. [Majadales silicícolas].

V. Vegetación nitrófila, viaria y arvense

ARTEMISIETEA VULGARIS Lohmeyer, Preising \& Tüxen in Tüxen $1950 \mathrm{ampl}$. RivasMartínez, Báscones, T.E. Díaz, Fernández González y Loidi 1991

+ Carthametalia lanati Brullo in Brullo \& Marceno 1985

* Carduo carpetani-Cirsion odontolepidis Rivas-Martínez, Penas y T.E Díaz 1986

46. Centaureo baeticae-Carlinetum corymbosae Pérez Latorre y Cabezudo ass. nova. [Cardales basófilos mesosupramediterráneos rondeños].

PEGANO HARMALAE-SALSOLETEA VERMICULATAE Br.-B1. \& O. Bolòs 1958 + Helichryso stoechadis-Santolinetalia squarrosae Peinado y Martínez Parras 1984

* Santolinion pectinato-canescentis Peinado y Martínez Parras 1984

47. Com. de Helichrysum italicum subsp. serotinum.[Tomillares nitrófilos basófilos].
STELLARIETEA MEDIAE R.Tx., Lohmeyer y Preising in R. Tx. 1950 em. Rivas-Martínez 1977

+ Chenopodietalia muralis Br.-B1. 1931

* Chenopodion muralis Br-B1. 1931.

48. Com. de Calendula arvensis. [Vegetación anual ruderal nitrófila].

+ Geranio purpurei-Cardaminetalia hirsutae Brullo in Brullo \& Marceno 1985

* Geranio pusilli-Anthriscion caucalidis RivasMartínez 1978

49. Com. de Geranium lucidum. [Pastizales escionitrófilos calcícolas].

50. Com. de Geranium purpureum. [Pastizales escionitrófilos serpentinícolas].

+ Bromenalia rubenti-tectori Rivas-Martínez y Izco 1977

* Taeniathero-Aegylopion geniculatae (Rivas Goday y Rivas-Martínez 1963) Rivas-Martínez e Izco 1977

51. Medicago rigidulae-Aegilopetum geniculatae Rivas-Martínez e Izco 1977. [Comunidades arvenses de corta talla].

VI. Vegetación rupícola

ADIANTETEA CAPILLI-VENERIS Br.-Bl. 1947

+ Adiantetalia capilli-veneris Br.-B1. 1931

* Adiantion capilli-veneris Br.-Bl. 1931

52. Trachelio coerulei-Adiantetum capilli-veneris O. Bolós 1957. [Vegetación de rocas rezumantes].

ANOMODONTO-POLYPODIETEA RivasMartínez 1975

+Anomodonto-Polypodietalia O. Bolòs y Vives in O. Bolòs 1957

* Polypodion serrulati (cambrici) Br.-Bl. in Br.-B1. \& col. 1952 corr.

53. Polypodietum serrati Br.-B1.- in Br.B1. \& col. 1952. [Vegetación pteridofítica vivaz de repisas terrosas].

* Anogrammion leptophyllae Bellot y Casaseca in Bellot 1967 
54. Selaginello-Anogrammetum leptophyllae R. Molinier 1937. [Comunidades pteridofíticas de taludes húmedos].

55. Asplenio-Saxifragetum gemmulosae Rivas-Martínez, Izco y Costa 1973. [Vegetación esciófila fisurícola de serpentinas].

ASPLENIETEA TRICHOMANIS (Br.-Bl, in Meier \& Br.-Bl. 1934) Oberdorfer 1977 + Asplenietalia petrarchae (glandulosi) Br.Bl. in Meier \& Br.-B1. 1934 ++ Tinguarrenalia siculae (Daumas, Quézel \& Santa 1952) Galán de Mera in Pérez Latorre, Galán de Mera, Deil y Cabezudo 1996

* Poterion ancistroidis Br.-Bl. 1934

56. Chaenorhino villosaeCampanuletum mollis Rivas Goday 1953. [Vegetación rupícola termófila y heliófila].

campanuletosum mollis

athamantetosum vayredanae Pérez Latorre y Cabezudo subass. nova [Variante orófila de grietas anchas y umbrías].

57. Sarcocapno baetici-Centaureetum clementei Asensi y Esteve 1977. [Vegetación espeluncícola heliófila].

+ Potentilletalia caulescentis Br.-Bl. in Br.B1. \& Jenny 1926

* Saxifragion camposii Cuatrecasas ex Quezel 1953

58. Rhamno pumili-Saxifragetum granatensis Pérez Latorre y Cabezudo ass. nova. [Vegetación rupícola basófila supraoromediterránea rondeña].

saxifragetosum granatensis

Var. de Hieracium baeticum. [Variante heliófila supramediterránea].

galietosum pulvinati Pérez Latorre y Cabezudo subass. nova. [Variante de dolomías].

+ Parietarietalia judaicae Rivas-Martínez (1955) 1960 em. nom. Oberdorfer 1977
* Parietario-Galion murale Rivas-Martínez ex Rivas Goday 1964

59. Parietarietum judaicae K. Buchwald 1952 (Arenes 1928) Oberdorfer 1977. [Vegetación rupícola herbácea nitrófila].

60. Stachydetum circinatae Fdez. Casas 1972. [Vegetación rupícola nitrófila de huecos terrosos].

+ Cheilanthetalia marantho-maderensis Sáenz y Rivas-Martínez 1979

* Phagnalo saxatilis-Cheilanthion maderensis Loisel 1970 corr. Sáenz y Rivas-Martínez 1979

61. Notholaeno marantae-Cheilanthetum guanchicae Pérez Carro, T.E. Díaz, Fernández Areces y Salvo 1989. [Vegetación pteridofítica rupícola-glerícola de serpentinas].

+ Sarcocapnetalia enneaphyllae Fdez. Casas 1972 em. Deil y Galán de Mera 1997

* Sarcocapnion crassifoliae Fdez. Casas 1972 em. Deil y Galán de Mera 1997

62. Sarcocapnetum baeticae Pérez Latorre y Cabezudo ass. nova. [incl. p. p. Sarcocapno-Centaureetum clementei Asensi y Esteve 1977]. [Vegetación espeluncícola esciófila].

+ Rumicetalia indurati (Rivas Goday 1964) Rivas Goday y Rivas-Martínez 1971

* Andryalo-Crambion (Rivas Goday y Esteve 1972) Rivas-Martínez, Izco y Costa 1973

63. Linario clementei-Andryaletum ramosissimae Rivas Goday y Esteve 1976. [Vegetación dolomitícola de gleras y taludes arenosos].

64. Com. de Armeria colorata. [Vegetación serpentinícola occidental de gleras y grietas terrosas].

65. Com. de Armeria carratracensis. [Vegetación serpentinícola oriental de gleras y grietas terrosas].

* Rumici-Dianthion lusitani Rivas-Martínez, Izco y Costa 1973 


\section{Asplenio billotii-Dianthetum lusitani} Pérez Latorre y Cabezudo ass. nova. [Comunidad silicícola mesomediterránea de grietas terrosas].

+ Thlaspietalia rotundifolii Br.-B1. 1936

* Dryopteridion submontanae.

67. Com. de Cystopteris fragilis. [Vegetación pteridofítica de simas, torcas y canchales umbríos supra-oromediterráneos].

* Platycapno saxicolae-Iberidion granatensis Rivas Goday y Rivas Martínez 1963

68. Com. de Silene boryi [Pastizales glerícolas vivaces]

VII. Vegetación de suelos húmedos, acuática, helofítica y anfibia

CHARETEA FRAGILIS Fukarek ex Krausch 1964

+ Charetalia hispidae Sauer 1937

* Charion vulgaris Krause 1981

69. Charetum vulgaris Krause 1969. [Vegetación algal de aguas meso-oligotrofas].

MOLINIO-ARRHENATHERETEA R. Tx. 1937 + Agrostietalia castellanae Rivas-Martínez in Rivas-Martínez, Costa, Castroviejo y Valdés 1980

*Agrostion castellanae Rivas Goday 1957 corr. Rivas Goday y Rivas-Martínez 1963

70. Com. de Holcus lanatus. [Pastizales de suelos arenosos silíceos temporalmente encharcados].

+ Holoschoenetalia Br.-B1. (1931) 1947

* Molinio-Holoschoenion Br.-B1. (1931) 1947

** Molinio-Holoschoenenion Br.-Bl. (1931) 1947

71. Cirsio monspessulaniHoloschoenetum vulgaris Br.-B1. 1931. [Juncales de fuentes].

72. Com. Scirpus holoschoenus [Juncales freatófitos]. var. de Galium viridiflorum. [Variante sobre serpentinas].

73. Galio viridiflori-Schoenetum nigricantis Rivas Goday y Esteve 1972. [Juncales serpentinícolas de junco negro].

schoenetosum nigricantis

molinietosum caeruleae Rivas Goday y Esteve 1972. [Variante hidrófila con Molinia]. + Plantaginetalia majoris R. Tx. \& Preising in R. Tx. 1950 em Rivas-Martínez 1987

* Agropyro repentis-Rumicion crispi Nordhagen 1940 em. R. Tx. 1950

** Mentho longifoliae-Juncenion inflexi RivasMartínez, Fernández González y Sánchez Mata 1986

74. Ranunculo macrophylli-Juncetum inflexi Pérez Latorre, Galán de Mera y Cabezudo ass. nova. [Juncales basófilos nitrófilos de suelos encharcados temporalmente].

+ Phalaridetalia coerulescentis Galán de Mera, Deil, Haug y Vicente Orellana 1997

* Gaudinio-Hordion Galán de Mera, Deil, Haug y Vicente Orellana 1997

75. Elymo repentis-Phalaridetum coerulescentis Pérez Latorre, Galán de Mera y Cabezudo ass. nova. [Pastizales higrófilos verticícolas rondeños].

MAGNOCARICI-PHRAGMITETEA Klika in Klika \& Novak pro. nom. inv.

+ Nasturtio-Glyceretalia Pignatti 1953

* Apion nodiflori Segal in Westhof \& Den Held 1969

76. Oenanthetum crocatae $\mathrm{Br}$.- $\mathrm{Bl}$., Berset \& P. Silva in Br.-B1. \& R. Tx. 1952. [Comunidad de helófitos de aguas corrientes oligotróficas].

77. Apietum nodiflori Maire 1924 pro nom. mut. [Comunidad de helófitos de aguas corrientes eutróficas].

78. Com. de Trifolium repens. [Césped higrófilo de fuentes nitrificadas]. 
Tabla 1

\begin{tabular}{lccccc}
\hline \multicolumn{4}{c}{$\begin{array}{c}\text { Pino halepensis-Juniperetum phoeniceae Pérez Latorre y Cabezudo ass. nova } \\
\text { (Quercetea ilicis, Pistacio-Rhamnetalia, Pino-Juniperion phoeniceae) }\end{array}$} \\
\hline${\text { Inventario } \mathrm{n}^{\circ}}_{\text {Orientación }}$ & 1 & 2 & 3 & 4 & 5 \\
Inclinación $\left({ }^{\circ}\right)$ & $\mathrm{S}$ & $\mathrm{S}$ & $\mathrm{S}$ & $\mathrm{S}$ & $\mathrm{S}$ \\
Altitud (m) & 45 & 40 & 45 & 45 & 35 \\
Cobertura $(\%)$ & 830 & 900 & 700 & 530 & 650 \\
Área $\left(\mathrm{m}^{2}\right)$ & 100 & 70 & 90 & 80 & 50 \\
Litología & 100 & 150 & 100 & 200 & 50 \\
& Dol. & Már. Dol. & Dol. & Dol.
\end{tabular}

Características y diferenciales

Juniperus phoenicea

Pinus halepensis

Juniperus oxycedrus

Ceratonia siliqua

Ulex baeticus

Rhamnus lycioides velutinus

$\begin{array}{lllll}+ & 2 & 2 & 1 & 3 \\ 3 & 2 & 1 & 5 & 2 \\ 2 & + & + & 1 & 1 \\ 1 & 1 & 2 & + & 3 \\ 2 & . & 1 & 1 & . \\ + & 1 & . & . & .\end{array}$

Características de unidades superiores

Chamaerops humilis

Pistacia lentiscus

Olea europaea sylvestris

Quercus ilex ballota

Rhamnus lycioides oleoides

Smilax aspera

Daphne gnidium

Aristolochia baetica

Asparagus acutifolius

Bupleurum gibraltaricum

Carex hallerana

Clematis flammula

Lonicera implexa

Osyris alba

Rubia peregrina

\section{Compañeras}

Rosmarinus officinalis

Cistus albidus

Thymus mastichina

Phlomis purpurea

Asperula hirsuta

Micromeria graeca

Brachypodium retusum

Melica minuta

Pinus pinaster

Pistacia terebinthus

Otros táxones: Avenula gervaisii subsp. arundana + , Helichrysum stoechas,+ Lapiedra martinezii + Polygala rupestris,+ Psoralea bituminosa + en 1; Phlomis lychnitis + , Stipa tenacissima 2 en 2; Hedera helix + , Argyrolobium zanonii + , Phagnalon rupestre + , Rosa canina,+ Teucrium lusitanicum + , Teucrium risanense + en 3; Nerium oleander + , Cistus monspeliensis + , Putoria calabrica + , Retama sphaerocarpa + , Sanguisorba minor +, Satureja obovata subsp obovata +, Urginea maritima + en 4; Ononis natrix 1, Ptilostemon hispanicus +. Carlina corymbosa + en 5.

Localidades.-1: Carril ladera S del Torrecilla. Proximidades de la Loma del Moro. Tolox. Málaga. 2: Cerca de los Llanos del Moro. Tolox. Málaga. 3: Por encima del nacimiento de Río Verde. Parauta. Málaga. 4: Pinar de Las Carnicerías. Tolox. Málaga. 5: Proximidades de Río Verde. Parauta. Málaga. 
Tabla 2

Rhamno myrtifolii-Juniperetum phoeniceae Molero Mesa y Pérez Raya 1987 abietetosum pinsaponis Pérez Latorre y Cabezudo subass. nova (Quercetea ilicis, Pistacio-Rhamnetalia, Pino-Juniperion phoeniceae)

Inventario $\mathrm{n}^{\circ}$

Orientación

Inclinación $\left(^{\circ}\right)$

Altitud (m)

Cobertura (\%)

Área $\left(\mathrm{m}^{2}\right)$

Litología

$\begin{array}{cc}1 & 2 \\ \mathrm{~N} & \mathrm{~N} \\ 30 & 10 \\ 1500 & 1200 \\ 40 & 60 \\ 200 & 100 \\ \text { Dol. } & \text { Cal. }\end{array}$

\section{3}

$\mathrm{N}$

15

1080

70

100

Dol.
4

$\mathrm{N}$

20

1100

60

200

Dol. Aren.

Características y diferenciales

Abies pinsapo

Juniperus phoenicea

Rhamnus myrtifolius

Ulex baeticus

Ononis reuteri

Pinus halepensis

Ulex baeticus bourgaeanus

2
3
+
$\vdots$
$\vdots$

$\begin{array}{ll}2 & + \\ 3 & 3 \\ + & + \\ 1 & 2 \\ 2 & 3\end{array}$

Características de unidades superiores

Daphne gnidium

Juniperus oxycedrus

Jasminum fruticans

Phillyrea media

Quercus ilex ballota

Ruscus aculeatus

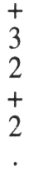

2

2

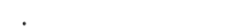

Compañeras

Lavandula lanata

Cistus albidus

Bupleurum spinosum

Echinospartum boissieri

Festuca scariosa

Helichrysum stoechas

Rosmarinus officinalis

Scabiosa turolensis grosii

Stipa tenacissima

Thymus mastichina

Arenaria erinacea

Carex hallerana

Cerastium gibraltaricum

Chaenorrhinum villosum

Helleborus foetidus

Phlomis lychnitis

Phlomis purpurea

Teucrium similatum

Thymus granatensis

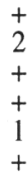

+
2
+
+
1
+

$+$

:

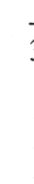

\begin{tabular}{|c|c|c|c|}
\hline+ & 2 & 1 & 2 \\
\hline 1 & 2 & 1 & + \\
\hline 1 & 2 & 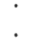 & 1 \\
\hline 1 & 3 & & . \\
\hline$\cdot$ & 1 & 1 & \\
\hline+ & 1 & 2 & + \\
\hline T & & + & 1 \\
\hline . & 3 & + & . \\
\hline+ & r & . & . \\
\hline+ & 2 & $\cdot$ & . \\
\hline . & 2 & $\dot{b}$ & $i$ \\
\hline . & & . & . \\
\hline . & 2 & 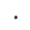 & . \\
\hline & & + & . \\
\hline $\begin{array}{l}+ \\
+\end{array}$ & & · & . \\
\hline
\end{tabular}

Otros táxones: Carex hallerana + , Convolvulus boissieri subsp. boissieri + , Erinacea anthyllis + , Helianthemum marifolium subsp. marifolium + , Jurinea pinnata + , Koeleria dasyphylla + en 1; Acinos alpinus subsp. meridionalis 2, Cerastium gibraltaricum 2, Crambe filiformis + , Helianthemum croceun var. croceum +, Phlomis crinita 2, Pinus pinaster + , Ptilostemon hispanicus 3, Putoria calabrica + en 2; Arisarum simorrhinum 1, Digitalis oscura subsp. laciniata + , Mercurialis tomentosa 1 en 3; Asperula hirsuta + Chaenorrhinum villosum + , Helichrysum italicum subsp. serotinum + , Melica minuta + en 4.

Localidades.- 1: Puerto de Los Hornillos. Yunquera. Málaga. 2: Carril de la Nava de San Luis al Puerto de Las Golondrinas. Tolox. Málaga. 3: Cañada de las Carnicerias. Tolox. Málaga. 4: Base del Cerro Alcazaba. Tolox. Málaga. 
Tabla 3

Paeonio broteroi-Abietetum pinsaponis Asensi y Rivas-Martínez 1976 juniperetosum phoeniceae Pérez Latorre y Cabezudo subass. nova (Quercetea ilicis, Pistacio-Rhamnetalia,Pino-Juniperion phoeniceae)

Inventario $\mathrm{n}^{\circ}$

Orientación

Inclinación $\left({ }^{\circ}\right)$

Altitud (m)

Cobertura $(\%)$

Área $\left(\mathrm{m}^{2}\right)$

Litología

$\begin{array}{cccccc}1 & 2 & 3 & 4 & 5 & 6 \\ \mathrm{~N} & \mathrm{~N} & \mathrm{~W} & \mathrm{~N} & \mathrm{~N} & \mathrm{~N} \\ 45 & 40 & 30 & 20 & 50 & 30 \\ 1460 & 1560 & 1650 & 1100 & 1320 & 1250 \\ 100 & 70 & 50 & 100 & 95 & 100 \\ 200 & 200 & 200 & 200 & 200 & 200 \\ \text { Cal. } & \text { Dol. } & \text { Cal. } & \text { Dol. } & \text { Dol. } & \text { Dol. }\end{array}$

Características y diferenciales de asociación

Abies pinsapo

Paeonia coriacea

Características y diferenciales de subasociación

Juniperus phoenicea

Ononis reuteri

$\begin{array}{cccccc}5 & 3 & 3 & 4 & 4 & 5 \\ \cdot & \cdot & \cdot & \cdot & \cdot & + \\ + & + & + & + & + & + \\ 1 & + & . & . & 1 & 2\end{array}$

Característica de variante

Pinus halepensis

Características de unidades superiores (Pistacio-Rhmanetalia, Quercetea ilicis)

Quercus ilex ballota

Hedera helix

Rubia peregrina

Juniperus oxycedrus

Daphne gnidium

Características de unidades superiores (Querco-Fagetea)

Daphne laureola latifolia

Helleborus foetidus

Quercus alpestris

Rosa canina

Berberis vulgaris

Crataegus monogyna brevispina

Acer granatense

Rosa micrantha

Sorbus aria

Taxus baccata

\section{Compañeras}

Cerastium gibraltaricum

Piptatherum paradoxum

Prunus prostrata

Ulex baeticus

Digitalis purpurea

Geranium lucidum

Geranium purpureum

Orobanche purpurea

Otros táxones: Bupleurum spinosum + en 1; Arenaria erinacea,+ Hormatophylla spinosa 1, Leontodon taraxacoides + en 2; Juniperus sabina 1, Cerastium glomeratum + , Linaria tristis + en $3 ;$ Phlomis purpurea + en 4; Cedrus atlantica + , Dactylis glomerata var. hispanica + , Festuca ampla subsp. ampla 1, Pinus sylvestris + , Thymus mastichina subsp. mastichina 1 en 5.

Localidades.- 1: Base Cerro Alcazaba. Proximidades del Arroyo de los Pilones. Tolox. Málaga. 2: Bajo el Picacho de Fatalandar. Tolox. Málaga 3: Tolox. Entre Cueva del Oso y Puerto de Los Valientes. Tolox. Málaga. 4: Carril al vivero de la Cueva del Agua. Yunquera. Málaga. 5: Final de la Cañada de Los Hornillos. Yunquera. Málaga. 6: Pinsapar de la Cañada de las Encinas. Yunquera. Málaga. 
Tabla 4

Pruno mahalebo-Berberidetum hispanicae Asensi y Rivas-Martínez 1979 prunetosum postratae Pérez Latorre y Cabezudo subass. nova (Querco-Fagetea, Prunetalia spinosae, Lonicero-Berberidion)

Inventario $\mathrm{n}^{\mathbf{0}}$
Orientación
Inclinación $\left(^{\circ}\right)$
Altitud $(\mathrm{m})$
Cobertura $(\%)$
Área $\left(\mathrm{m}^{2}\right)$
Litología

Características de asociación

Berberis vulgaris

Prunus mahaleb

$\begin{array}{ccc}1 & 2 & 3 \\ \mathrm{~S} & - & \mathrm{NE} \\ 0 & 0 & 10 \\ 1720 & 1700 & 1710 \\ 30 & 100 & 100 \\ 300 & 100 & 200 \\ \text { Cal. } & \text { Cal. } & \text { Cal. }\end{array}$

Características y diferenciales de subasociación

Prunus prostrata

Rhamnus saxatilis

Crataegus granatensis

Geum heterocarpum

Rosa micrantha

Juniperus sabina

Cotoneaster racemiflora

Rosa nitidula

Rosa scuarrosa

$\begin{array}{lll}2 & 4 & 4 \\ + & \cdot & \end{array}$

Características de unidades superiores

Daphne laureola subsp. latifolia

Helleborus foetidus

Rosa canina

\section{Compañeras}

Acer granatense

Acer monspessulanum

Quercus alpestris

Abies pinsapo

Bupleurum spinosum

Geranium molle

Ranunculus macrophyllus

Sorbus aria

$\begin{array}{lll}1 & + & 1 \\ + & + & + \\ 2 & 1 & 1 \\ + & + & + \\ + & . & + \\ 2 & . & 1 \\ . & . & + \\ . & . & 1 \\ . & 2 & .\end{array}$

Otras táxones: Arun italicum subsp. italicum + , Cirsium echinatum + , Hippocrepis scabra subsp. baetica + , Juniperus communis subsp. communis 1, Taxus baccata + , Valerianella carinata + en 1; Bromus hordaceus r, Carex divulsa r, Festuca scariosa 1, Galium aparine + , Geranium lucidum 1, Lotus corniculatus 1, Orobanche purpurea + , Rumex acetosella + , Trifolium dubium 1, Veronica hederifolia subsp. triloba + en 2; Juniperus phoenicea subsp. phoenicea 1, Orobanche haenseleri + , Rhamnus pumilus + , Teucrium lerrouxi + en 3 .

Localidades.- 1: Entre Los Pilones y Cerro Alto. Trocha de la Serranía de Ronda. Tolox. Málaga. 2: Proximidades del Puerto de Los Pilones. Tolox. Málaga. 3: Cerro Plazoleta, por detrás del Pilar de Tolox. Tolox. Málaga. 
Tabla 5

Abieto pinsapo-Juniperetum sabinae Pérez Latorre y Cabezudo ass. nove (Pino-Juniperetea, Pino-Juniperetalia, Pino-Juniperion sabinae)

Inventario $\mathrm{n}^{\circ}$

Orientación

Inclinación $\left(^{\circ}\right)$

Altitud (m)

Cobertura (\%)

Área $\left(\mathrm{m}^{2}\right)$

Litología

Características y diferenciales de asociación

Juniperus sabina

Juniperus communis hemisphaerica

Abies pinsapo

Juniperus phoenicea

Ononis reuteri

Características de unidades superiores (Pino-Juniperetea)

Prunus prostrata

Rosa sicula

Geum heterocarpum

Características de unidades superiores (Querco-Fagetea)

Helleborus foetidus

Berberis vulgaris

Daphne laureola latifolia

Taxus baccata

Acer granatense

Crataegus granatensis

Hyacinthoides hispanica

Quercus alpestris

Sorbus aria

Acer monspessulanum

Rhamnus saxatilis

Compañeras

Hormatophylla spinosa

Festuca scariosa

Bupleurum spinosum

Cerastium gibraltaricum

Cystopteris fragilis

Erodium cheilanthifolium

Helichrysum italicum serotinum

Linaria tristis

Saxifraga granulata

Arenaria erinacea

Erinacea anthyllis

Poa ligulata

Acinos rotundifolius

Arenaria armerina

Astragalus sempervirens nevadensis

Carlina corymbosa

Doronicum plantagineum

Erysimum rondae

Geranium lucidum

Helianthemum marifolium

Helictotrichon filifolium arundanum

Koeleria dasyphylla

Leucanthemum arundanum

Ranunculus gramineus

Sanguisorba minor magnolii

Saxifraga globulifera

Scabiosa turolensis grosii

Sedum nevadense

Verbascum giganteum

Otros táxones: Leucanthemum arundanum +, Ranunculus gramineus + en 3; Doronicum plantagineum 1 en 4; Acinos rotundifolius + , Astragalus nevadense 2, Erysimum rondae + en $6 ;$ Carlina corymbosa + , Verbascum giganteum + en 7 Arenaria armerina + , Geranium lucidum + , Helianthemum marifolium + , Helictotrichon arundanum,+ Koeleria dasyphylla + , Sanguisorba magnolii + , Saxifraga globulifera + , Scabiosa turolensis subsp. grosii + , Sedum nevadense 1 en 8.

Localidades.-1: Quejigar de Tolox. Ronda. Málaga. 2 y 8: Cara W del Torrecilla. Tolox. Málaga. 3: Tolox. Torrecilla. Tolox. Málaga. 4, 5 y 7: Falda del Torrecilla. Tolox. Málaga. 6: Puerto de los Pilones. Ronda. Málaga. 
Tabla 6

Cytiso plumosi-Ulicetum baetici Nieto Caldera, Pérez Latorre y Cabezudo ass. nova ulicetosum baetici, erinaceetosum Pérez Latorre y Cabezudo subass. nova (Rosmarinetea, Rosmarinetalia, Micromerio-Coridothymon)

\begin{tabular}{lccccccccc}
\hline${\text { Inventario } n^{\circ}}^{\circ}$ & 1 & 2 & 3 & 4 & 5 & 6 & 7 & 8 & 9 \\
Orientación & $\mathrm{W}$ & $\mathrm{E}$ & $\mathrm{W}$ & $\mathrm{SW}$ & $\mathrm{SW}$ & $\mathrm{N}$ & $\mathrm{SW}$ & SSW & NW \\
Inclinación $\left(^{\circ}\right)$ & 30 & 30 & 10 & 20 & 10 & 10 & 10 & 10 & 0 \\
Altitud $(\mathrm{m})$ & 1300 & 1300 & 1200 & 1130 & 1100 & 1300 & 1350 & 1100 & 1050 \\
Cobertura $(\%)$ & 70 & 40 & 60 & 90 & 70 & 60 & 80 & 80 & 50 \\
Área $\left(\mathrm{m}^{2}\right)$ & 200 & 100 & 100 & 100 & 100 & 200 & 100 & 100 & 200 \\
Litología & Cal. & Cal. & Cal. & Cal. & Cal. & Cal. & Cal. & Cal. & Cal.
\end{tabular}

Características y diferenciales

Cytisus fontanesi plumosus

Ulex baeticus baeticus

Helianthemum appenninum asperum

Phlomis crinita

Característica de subasociación

Erinacea anthyllis

Características de unidades superiores

Phlomis lychnitis

Ptilostemon hispanicus

Asperula hirsuta

Phlomis purpurea

Bupleurum spinosum

Cistus albidus

Compañeras

Thymus mastichina mastichina

Crataegus monogyna brevispina

Asphodelus macrocarpus rubescens

Echium albicans

Quercus ilex ballota

Cerastium gibraltaricum

Helichrysum stoechas

Sanguisorba minor

Anthyllis vulneraria

Rhamnus myrtifolius

Rubia peregrina

Stipa tenacissima

Teucrium similatum

Abies pinsapo

Carlina corymbosa

Cirsium echinatum

Convolvulus meonanthus

Crambe filiformis

Dactylis glomerata hispanica

Daphne gnidium

Dianthus boissieri

Erodium cheilanthifolium

Festuca capillifolia

Helictotrichon filifolium arundanum

Iris planifolia

Leuzea conifera

Linum strictum

Lonicera etrusca

Cal. Cal. Cal

Mantisalca salmantica

Melica minuta

Ononis reuteri

Piptatherum paradoxum

Rosa canina

Santolina canescens

Scabiosa turolensis grosii

Thymus baeticus

Cheilanthes acrosticha

$\begin{array}{lllllllll}2 & 1 & + & + & 2 & + & + & + & 2 \\ 4 & 3 & + & 4 & 4 & 1 & 3 & 2 & 3 \\ 1 & 1 & 2 & 1 & 2 & 1 & . & + & . \\ 1 & 1 & 1 & . & . & 2 & +\end{array}$

Otros táxones: Acer monspessulanum + , Androsece maxima,+ Bromus matritensis,+ Erodium cicutarium,+ Eryngium campestre,+ Euphorbia exigua,+ Linaria tristis,+ Melilotus sulcata + , Onopordum illyricum 1, Plantago afra + , Poa ligulata + , Quercus faginea,+ Scorpiurus sulcatus + en $1 ;$ Alyssum montanum + Argyrolobium zanonii + , Armeria longiaristata + , Astragalus glaux,+ Bellis sylvestris,+ Biscutella vicentina,$+ B$. valentina,+ Festuca ampla + , Helictotrichon velutinum,+ Ononis pusilla,+ Pinus pinaster 1 , Salvia argentea + , Sedum sediforme + , Stipa gigantea + , Stipa offneri + , Xeranthemum inapertum + en $2 ;$ Astragalus echinatus + , Cuscuta epithymum + , Hordeum bulbosum + , Jasonia glutinosa + , Limum strictum + , Rosa micrantha + , Sanguisorba magnolii,+ Scorzonera hispanica,+ Teucrium risanense + en $4 ;$ Allium pallens + , Brachypodium retusum 2, Gaudinia fragilis + , Rosa sicula x canina + en $5 ;$ Asperula scabra 1 , Achillea odorata + , Anthemis arvensis + , Berberis vulgaris + , Cytisus grandiflorus +, Jasminum fruticans +, Prumus spinosa +, Rosa pouzinii +, Viscum cruciatum + en 6; Helianthemum marifolium 1, Picnomom acarna + en $7 ;$ Asplenium ceterach + , Biscutella sempervirens + , Chaenorrhinum villosum + , Cheilanthes acrosticha,+ Echinospartium boissieri 1, Marrubium vulgare,+ Musgos,+ Putoria calabrica,+ Thapsid garganica + , Urginea maritima $+\operatorname{en} 8 ;$ Agrostis reuteri + , Bellis perennis,+ Galium verrucosum,+ Gynandriris sisyrinchium 1 , Helianthemum rotundifolium 2 , Thapsia villosa $1 \mathrm{cn} 9$.

Localidades.- 1: Las Carboneras. Ronda. Málaga. 2: Proximidades del Cortijo Quejigales, cerro al sur del Cerro de la Yedra. Ronda. Málaga. 3: Proximidades Cueva Bermeja. Ronda. Málaga. 4: Proximidades Cortijo de la Sardina. Ronda. Málaga. 5: Entre Tajo Pompeya y Cueva Bermeja. Ronda. Málaga. 6. Desvío al carril del Cortijo de Lifa, entre Cortijo del Lirio y Las Atalayas. Ronda. Málaga. 7: $\mathrm{S}^{a}$ Hidalga, subida al pico desde cl repetidor. 8: $\mathrm{S}^{a}$ Hidalga, Cerro Castillejos. Ronda. Málaga. 9: Proximidades del Cortijo Molillo. Ronda. Málaga. 
Tabla 7

Astragalo nevadensis-Bupleuretum spinosi Pérez Latorre y Cabezudo ass. nova (Rosmarinetea, Rosmarinetalia, Xeroacantho-Erinaceion)

\begin{tabular}{lcccccccccc}
\hline Inventario $\mathrm{n}^{\mathbf{0}}$ & 1 & 2 & 3 & 4 & 5 & 6 & 7 & 8 & 9 & 10 \\
Orientación & - & $\mathrm{S}$ & $\mathrm{N}$ & $\mathrm{W}$ & $\mathrm{E}$ & $\mathrm{E}$ & $\mathrm{N}$ & $\mathrm{S}$ & $\mathrm{N}$ & $\mathrm{NE}$ \\
Inclinación $\left(\left(^{\circ}\right)\right.$ & 0 & 5 & 5 & 15 & 30 & 30 & 10 & 10 & 20 & 25 \\
Altitud $(\mathrm{m})$ & 1700 & 1720 & 1700 & 1750 & 1670 & 1480 & 1750 & 1720 & 1440 & 1600 \\
Cobertura $(\%)$ & 80 & 40 & 60 & 80 & 50 & 40 & 50 & 25 & 75 & 80 \\
Área $\left(\mathrm{m}^{2}\right)$ & 100 & 300 & 100 & 300 & 200 & 200 & 300 & 200 & 75 & 100 \\
Litología & Cal. & Cal. & Dol. & Cal. & Cal. & Cal. & Cal. & Cal. & Dol. & Cal.
\end{tabular}

Características y diferenciales de asociación

Bupleurum spinosum.

Astragalus sempervirens nevadensis

Phlomis crinita

Ononis reuteri

Erodium cheilanthifolium

Erysimum rondae

Veronica fontqueri

Koeleria dasyphylla

Arenaria erinacea

Características de unidades superiores

Erinacea anthyllis

Hormatophylla spinosa

Cerastium gibraltaricum

Helianthemum appenninum asperum

Scabiosa turolensis grosii

Arenaria armerina armerina

Thymus baeticus

Cistus albidus

Helianthemum appenninum

Lavandula lanata

Armeria villosa

Compañeras

Helleborus foetidus

Festuca scariosa

Cirsium echinatum

Juniperus sabina

Orobanche purpurea

Berberis vulgaris

Crataegus granatensis

Helianthemum marifolium

Helichrysum italicum serotinum

Poa ligulata

Prunus prostrata

Sanguisorba minor

Abies pinsapo

Acinos rotundifolius

Helichrysum stoechas

Juniperus communis hemisphaerica

Juniperus oxycedrus

Picnomon acarna

Rhamnus saxatilis

Verbascum giganteum

Helianthemum cinereum rotundifolium

Juniperus phoenicea

Linaria tristis

Quercus alpestris

Santolina canescens

Thymus mastichina

Clypeola jonthlaspi microcarpa

$\begin{array}{llllllllll}2 & 3 & 1 & 1 & 2 & 4 & 3 & 2 & 3 & 3 \\ 2 & 2 & . & 1 & 1 & + & 4 & + & . & + \\ . & 1 & . & + & . & + & + & . & + & 1 \\ . & . & . & . & + & 2 & + & + & 2 & . \\ . & + & + & . & 1 & + & . & 1 & . & . \\ . & + & + & + & . & . & + & . & . & + \\ . & i & . & + & . & . & + & . & . & + \\ . & 1 & . & . & . & . & . & . & + & + \\ . & . & . & . & + & . & 1 & . & . & +\end{array}$

Otros táxones: Clypeola microcarpa + , Galium aparine,+ Geum heterocarpum + , Hippocrepis baetica + , Hypericum perforatum,+ Legousia falcata + , Orobanche minor 1, Poa trivialis + en 2; Carduus rivasgodayanus + , Cichorium pumilum + , Erodium cicutarium + Euphorbia pinea + , Filago lutescens + Galium minutulum + , Herniaria lusitanica + , Leontodon longirrostris,+ Minuartia hybrida + , Viola demetria + en 3; Carlina corymbosa + , Lotus subbiflorus + , Festuca boissieri +, Galium baeticum + , Teucrium lerrouxi 1 en 4; Asplenium ceterach +, Biarum arundanum +, Quercus ballota + en 6; Anthyllis vulneraria,+ Bunium macuca,+ Daphne latifolia + , Festuca hystris 1, Geranium purpureum + en 8; Dactylis hispanica +, Saxifraga globulifera + en 9; Koeleria humilis + , Teucrium similatum + en 10 .

Localidades -1: Quejigar de Tolox. Ronda. Málaga. 2: Entre Los Pilones y Cerro Alto. Trocha de la Serranía de Ronda. Tolox. Málaga.

3: Entre Cerro Alto y cañada de las Carnicerías. Tolox. Málaga. 4: Peñón de Enamorados. Ronda. Málaga. 5: Cerro Alcazaba. Tolox. Málaga.

6: Base de cerro Alcazaba. Tolox. Málaga. 7: Repetidor del Puerto de los Pilones. Ronda. Málaga. 8: Bajo cerro Plazoleta. Tolox. Málaga. 9:

Senda a los Hornillos, cortafuegos frente al Cerro Picacho. Yunquera. Málaga. 10: Senda a Enamorados. Yunquera. Málaga. 
Tabla 8

Genisto viciosoi-Velletum spinosae Pérez Latorre y Cabezudo ass. nova (Rosmarinetea, Rosmarinetalia, Xeroacantho-Erinacion)

Inventario $\mathrm{n}^{\circ}$

Orientación

Inclinación $\left(^{\circ}\right)$

Altitud (m)

Cobertura $(\%)$

Área $\left(\mathrm{m}^{2}\right)$

Litología

1

NW

30

1500

40

50

Dol.

\section{2}

$\mathrm{NW}$

40

1570

30

100

Dol.
3

$\mathrm{N}$

10

1670

50

200

Dol.

\section{Características y diferenciales}

Genista longipes viciosoi

Vella spinosa

Teucrium lerrouxi

Ulex baeticus bourgaeanus

1

1

$+$

1

Características de unidades superiores

Bupleurum spinosum

Erinacea anthyllis

Helianthemum cinereum rotundifolium

Asperula aristata scabra

Echinospartum boissieri

Linum narbonense

Lithodora fruticosa

Santolina canescens

\section{Compañeras}

Arenaria erinacea

Convolvulus boissieri

Juniperus phoenicea

Thymus granatensis

Koeleria vallesiana humilis

Festuca hystrix

Poa ligulata

Abies pinsapo

Anthyllis vulneraria

Fumana ericifolia

Galium baeticum

Rhamnus myrtifolius

Jurinea pinnata

Jurinea humilis

Scabiosa turolensis grossi

Helianthemum appeninum

Cerastium boissieri

Berberis hispanica

Carduus echinatus

\begin{tabular}{|c|c|c|}
\hline+ & + & + \\
\hline 1 & 1 & 1 \\
\hline 1 & 1 & + \\
\hline+ & + & 1 \\
\hline+ & + & 1 \\
\hline+ & + & + \\
\hline 1 & 1 & . \\
\hline+ & . & . \\
\hline+ & $\cdot$ & . \\
\hline $\begin{array}{l}+ \\
+\end{array}$ & $\cdot$ & . \\
\hline l & 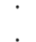 & $\cdot$ \\
\hline & . & + \\
\hline & . & + \\
\hline & + & . \\
\hline & . & + \\
\hline & . & + \\
\hline & . & r \\
\hline & . & + \\
\hline
\end{tabular}

Localidades.- 1, 2 y 3: Puerto de Los Hornillos. Yunquera. Málaga. 
Tabla 9

Seselido granatensis-Festucetum hystricis Martínez Parras, Peinado y Alcaraz 1985

arenarietosum erinacei Pérez Latorre y Cabezudo subass. nova

(Festuco-Ononidetea, Festuco-Poetalia, Minuartio-Poion ligulatae)

Inventario $\mathrm{n}^{\circ}$

Orientación

Inclinación $\left({ }^{\circ}\right)$

Altitud (m)

Cobertura (\%)

Área $\left(\mathrm{m}^{2}\right)$

Litología $\begin{array}{lll}1 & 2 & 3\end{array}$

- $\quad \mathrm{N}$

$\begin{array}{lll}0 & 0 & 45\end{array}$

$\begin{array}{lll}1750 & 1660 & 1840\end{array}$

$\begin{array}{lll}60 & 20 & 10\end{array}$

$\begin{array}{lll}50 & 10 & 100\end{array}$

Cal. Cal. Cal.

$\begin{array}{ccc}4 & 5 & 6 \\ \mathrm{~N} & - & \mathrm{N} \\ 30 & 0 & 10 \\ 1900 & 1900 & 2020 \\ 10 & 5 & 25 \\ 100 & 50 & 50 \\ \text { Cal. } & \text { Dol. } & \text { Cal. }\end{array}$

Características y diferenciales de asociación y subasociación

Arenaria erinacea

Erodium cheilanthifolium

Festuca hystrix

$\begin{array}{llllll}+ & + & + & 1 & + & 1 \\ 1 & 3 & 1 & 1 & 2 & + \\ . & + & + & 1 & + & 1\end{array}$

\section{Características de variantes}

Helianthemum marifolium

Poa bulbosa

Koeleria dasyphylla

Sideritis glacialis

Armeria filicaulis

\section{Características de unidades superiores}

Poa ligulata

Helianthemum cinereum rotundifolium

Helianthemum canum

Dianthus subacaulis

$\begin{array}{cccccc}+ & + & + & + & + & . \\ 1 & \cdot & \cdot & \cdot & \cdot & + \\ + & \cdot & + & \cdot & \cdot & \cdot \\ \cdot & \cdot & \cdot & \cdot & \cdot & + \\ \cdot & \cdot & \cdot & \cdot & \cdot & +\end{array}$

\section{Compañeras}

Bupleurum spinosum

Helichrysum italicum serotinum

Hormatophylla spinosa

Sedum nevadense

Cerastium gibraltaricum

Juniperus sabina

Orobanche purpurea

Prunus prostrata

Saxifraga granulata

$\begin{array}{cccccc}3 & 2 & 1 & 1 & + & 2 \\ + & \cdot & \cdot & + & + & . \\ . & . & . & . & . & 1 \\ . & . & . & . & . & 2\end{array}$

Otros táxones: Arenaria armerina subsp. armerina 1, Astragalus glaux + , Astragalus hamosus 1, Bellis sylvestris 1, Cirsium echinatum + , Erysimum rondae + , Urginea maritima + , Leontodon longirrostris + , Leuzea conifera 1, Linaria tristis,+ Muscari comosum + , Narcissus assoanus subsp. praelongus +, Ornithogalum ortophyllum subsp. baeticum + , Ranunculus spicatus subsp. blephricarpus 2, Sanguisorba minor + , Rumex acetosella + , Taraxacum obovatum subsp. obovatum + en 1 ; Androsace maxima + , Ononis pusilla + en 2; Helleborus foetidus + , Saxifraga globulifera + en 3; Helictotrichon filifolium subsp. arundanum + , Rhamnus saxatilis + , Santolina canescens + , Sedum caespitosum + , Sedum dasyphyllum $\mathrm{r}+$, Teucrium similatum + en 4; Teucrium lerrouxi + , Thymus granatensis subsp. granatensis +en 5 ; Koeleria vallesiana + , Jurinea humilis 1 , Erinacea anthyllis + , Astragalus granatensis + , Vella spinosa + , Acinos alpinus + , Odontites longiflora + en 6 .

Localidades.-1: Quejigar de Tolox, entre Puerto de Los Pilones y Cerro Alto. Ronda. Málaga. 2:Cumbre rocosa, junto a Cerro Alcazaba. Tolox. Málaga. 3: Tolox. Ladera W del Torrecillas. Tolox. Málaga. 4: Cuerda del Torrecillas. Tolox. Málaga. 5: Por debajo del pico del Torrecillas. Tolox. Málaga. 6: Sierra Tejeda. La Maroma. Canillas de Aceituno. Málaga. (Nieto Caldera, 1987). 
Tabla 10

Arenarietum arundanae Pérez Latorre y Cabezudo ass. nova (Helianthemetea, Helianthemetalia, Omphalodion brassicifoliae)

\begin{tabular}{lccccc}
\hline Inventario ${ }^{\circ}$ & 1 & 2 & 3 & 4 & 5 \\
Orientación & - & $\mathrm{W}$ & $\mathrm{N}$ & $\mathrm{N}$ & - \\
Inclinación $\left({ }^{\circ}\right)$ & 0 & 0 & 40 & 10 & 0 \\
Altitud $(\mathrm{m})$ & 1040 & 1550 & 1600 & 1350 & 1310 \\
Cobertura $(\%)$ & 15 & 20 & 50 & 20 & 30 \\
Área $\left(\mathrm{m}^{2}\right)$ & 5 & 3 & 20 & 4 & 50 \\
Litología & Dol. & Dol. & Dol. & Dol. & Dol.
\end{tabular}

Características y diferenciales de asociación

Arenaria arundana

Chaenorrhinum rubrifolium

Viola demetria

Características de unidades superiores

Asterolinon linum-stellatum

Leontodon longirrostris

Minuartia hybrida

Narduroides salzmannii

Crucianella angustifolia

Rumex bucephalophorus

Brachypodium distachyon

Bombycilaena discolor

Desmazeria rigida

Hornungia petraea

Jonopsidium prolongoi

Prolongoa hispanica

Silene germana

Trifolium scabrum

Viola kitaibeliana

Compañeras

Bromus matritensis

Cynosurus elegans

Erodium cicutarium

Galium parissiense

Anagallis arvensis

Anthemis arvensis

Brassica repanda

Bromus rubens

Carduus tenuiflorus

Centranthus macrosiphon

Erodium aethiopicum

Erodium moschatum

Galium minutulum

Galium murale

Geranium lucidum

Helianthemum appenninum

Herniaria lusitanica

Hippocrepis scabra baetica

Holosteum umbellatum

Koeleria vallesiana humilis

Lepidium hirtum calycotrichum

Linaria tristis

Micropyrum tenellum

Minuartia mediterranea

Muscari atlanticum

Neatostema apulum

Plantago bellardii

Plantago coronopus

Poa ligulata

Sedum amplexicaule tenuifolium

Trifolium tomentosum

Vulpia hispanica

1

.

$+$

$\begin{array}{lll}1 & 3 & + \\ + & + & .\end{array}$

Otros táxones: Hippocrepis baetica 1, Plantago bellardii 1, Plantago coronopus 1, Trifolium tomentosum + en 1 ; Carduus tenuiflorus + , Erodium aethiopicum + , Helianthemum apenninum + , Holosteum umbellatum + , Koeleria humilis + , Minuartia mediterranea + , Sedum tenuifolium + en $2 ;$ Brassica repanda,+ Erodium moschatum 1 , Herniaria lusitanica 1, Poa ligulata + en 3; Galium murale +, Linaria tristis +, Vulpia hispanica 1 en 4; Centranthus macrosiphon + , Geranium lucidum +, Lepidium calycotrichum + , Muscari atlanticum + , Neatostema apulum + en 5.

Localidades.- 1: Entre entrada carril Quejigales y el Navasillo. Ronda. Málaga. 2: Subida a los Pilones. Ronda. Málaga. 3: Entre Peñón de Ronda y Cañada de las Carnicerias. Ronda. Málaga. 4: Cañada de Los Hornillos. Yunquera. Málaga.

5: Carril de subida a Quejigales. Proximidades a las Turquillas. Ronda. Málaga. 
Tabla 11

Centaureo baeticae-Carlinetum corymbosae Pérez Latorre y Cabezudo ass. nova (Artemisietea, Carthametalia lanati, Carduo-Cirsion odontolepidis)

\begin{tabular}{lcccccccc}
\hline Inventario $\mathrm{n}^{\mathbf{0}}$ & 1 & 2 & 3 & 4 & 5 & 6 & 7 & 8 \\
Orientación & - & $\mathrm{N}$ & $\mathrm{W}$ & - & $\mathrm{NE}$ & - & $\mathrm{NW}$ & $\mathrm{W}$ \\
Inclinación $\left({ }^{\circ}\right)$ & 0 & 5 & 10 & 0 & 10 & 0 & 5 & 5 \\
Altitud $(\mathrm{m})$ & 1000 & 1100 & 1150 & 1720 & 1120 & 1150 & 1150 & 1000 \\
Cobertura $(\%)$ & 80 & 30 & 60 & 80 & 30 & 100 & 20 & 40 \\
Area $\left(\mathrm{m}^{2}\right)$ & 200 & 50 & 100 & 300 & 100 & 50 & 10 & 100 \\
Litología & Cal. & Dol. & Cal. & Cal. & Cal. & Cal. & Cal. & Cal.
\end{tabular}

Características y diferenciales de asociación

Carlina corymbosa

Centaurea pullata baetica

Carduus tenuiflorus

Cirsium echinatum

Onopordum illyricum

Eryngium dilatatum

$\begin{array}{ll}+ & 2 \\ + & + \\ 1 & + \\ \cdot & 1 \\ \cdot & \cdot \\ \cdot & \end{array}$

3
$:$
$:$
$:$

$\begin{array}{lllll}1 & + & 3 & + & + \\ + & + & \cdot & . & . \\ i & + & \cdot & + & . \\ . & i & \cdot & + & + \\ . & . & + & 2 & .\end{array}$

\section{Características de unidades superiores}

Centaurea calcitrapa

Eryngium campestre

Picnomon acarna

Scolymus hispanicus

Carduus pycnocephalus

Cynara baetica

Cynara humilis

Silybum marianum

Verbascum giganteum

Carlina racemosa

\section{Compañeras}

\section{Linum tenue tenue}

Erodium cicutarium

Silene vulgaris

Aegilops geniculata

Aegilops triuncialis

Convolvulus arvensis

Erodium primulaceum

Leontodon longirrostris

Melilotus indica

Plantago lagopus

Sanguisorba minor

Thymus mastichina

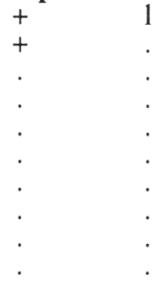$$
2
$$

$\dot{2}$
+
+
.
.
.
.

+
+
+
5
5
+
+

$\begin{array}{cccc}+ & + & 1 & 1 \\ 2 & 1 & + & 1 \\ 1 & i & + & + \\ 1 & i & 1 & 4 \\ . & . & . & + \\ . & . & + & . \\ + & . & . & + \\ . & . & . & + \\ . & . & . & +\end{array}$

Otros táxones: Astragalus glaux +, Cerastium glomeratum + , Hippocrepis biflora + , Lamium amplexicaule + , Ornithogalum ortophyllum subsp. baeticum + , Reichardia picroides + , Scorpiurus muricatus + , Scorzonera gramminifolia + , Sherardia arvensis +, Trifolium campestre 1 en 1; Atropa baetica 3, Euphorbia characias + en 2; Crucianella angustifolia + , Desmazeria rigida subsp. rigida + , Euphorbia exigua subsp. exigua + , Filago micropodioides + , Plantago lanceolata,+ Poa bulbosa + , Velezia rigida + en 3; Aira caryophyllea subsp. caryophyllea,+ Arrhenatherum elatius + , Biarum arundanum + , Bromus intermedius + , Hieracium pseudopilosella 1 , Linaria tristis,+ Poa annua + , Poa ligulata var. ligulata 2, Poa trivialis + , Ranunculus spicatus subsp. blepharicarpus + , Rumex acetosella subsp. angiocarpus + , Teucrium similatum + , Trifolium cherleri 1, Trifolium glomeratum + , Trifolium scabrum + , Viola demetria +, Viola kitaibeliana + en 4; Anthemis arvensis +, Bromus metritensis + , Crambe filiformis + , Dactylis glomerata var. hispanica 1, Helianthemum appenninum subsp. asperum 2, Mucizonia hispida + , Scandix pecten-veneris 1 en 5; Anthyllis vulneraria + , Asteriscus aquaticus + , Avena sterilis + , Carex flacca subsp. serrulata + , Cuscuta epithymum +, Elymus repens subsp. repens +, Festuca capillifolia +, Galium baeticum +, Gaudinia fragilis subsp. fragilis + , Holcus lanatus + , Juncus inflexus + , Lolium rigidum + , Micropyrum tenellum + , Ononis repens subsp. australis 1, Phalaris coerulescens 1, Plantago albicans + , Polygala monspeliaca + , Scandix australis + , Trifolium stellatum 1 en 6; Cerastium gibraltaricum + , Phlomis lychnitis + en 8.

Localidades.-1: Llano de las Conejeras. Parauta. Málaga. 2: Base de la Cañada de Las Ánimas. Ronda. Málaga. 3: Proximidades Cueva Bermeja. Ronda. Málaga 3: Entre Los Pilones y Cerro Alto. Trocha de la Serranía de Ronda. Tolox. Málaga. 5: Camino del Pto. de Quejigales, pasado Cortijo Sabinar Alto. Ronda. Málaga. 6: Proximidades del Pto. La Sardina. Ronda. Málaga. 7: Carril al Cortijo de Lifa, proximidades del Carramolo del Queso. Ronda. Málaga. 8: Entre Peñón de Ronda y Cortijo de Ronda. Ronda. Málaga. 
Tabla 12

Chaenorrhino villosae-Campanuletum mollis Rivas Goday 1953

athamantetosum vayredanae Pérez Latorre y Cabezudo subass. nova (Asplenietea, Asplenietalia, Poterion ancistroides)

\begin{tabular}{lcccc}
\hline Inventario $^{\circ}$ & 1 & 2 & 3 & 4 \\
Orientación & W & W & E & W \\
Inclinación $\left({ }^{\circ}\right)$ & 90 & 90 & 90 & 90 \\
Altitud $(m)$ & 1100 & 1680 & 1100 & 1100 \\
Cobertura (\%) & 10 & - & 20 & 5 \\
Área $\left(\mathrm{m}^{2}\right)$ & 50 & 3 & - & 10 \\
Litología & Már. & Cal. & Dol. & Dol.
\end{tabular}

Características y diferenciales de subasociación

Athamanta vayredana

Centaurea clementei

Scabiosa turolensis subsp. grosii

Silene andryalifolia

Características de asociación

Campanula velutina

Chaenorrhinum villosum

Características de unidades superiores

Leontodon taraxacoides

Sedum dasyphyllum

\section{Compañeras}

Teucrium similatum

Rhamnus myrtifolius

Cephalaria leucantha

Helictotrichon filifolium arundanum

Sanguisorba minor

\begin{tabular}{|c|c|c|c|}
\hline 1 & 1 & 2 & 1 \\
\hline . & & 1 & . \\
\hline . & + & . & . \\
\hline . & . & + & . \\
\hline+ & + & . & + \\
\hline . & + & + & + \\
\hline . & + & . & . \\
\hline$\cdot$ & . & . & + \\
\hline+ & + & . & . \\
\hline$\cdot$ & . & + & 1 \\
\hline . & + & . & . \\
\hline . & + & . & . \\
\hline & . & . & + \\
\hline
\end{tabular}

Localidades.- 1: Carril base del Torrecilla. Tolox. Málaga. 2: Tolox. Cerro Alcazaba. Tolox. Málaga. 3: Carril base del Torrecilla. Tolox. Málaga. 4: Carril base del Torrecilla. Tolox. Málaga.

Tabla 13

\begin{tabular}{|c|c|c|c|}
\hline \multicolumn{4}{|c|}{$\begin{array}{c}\text { Sarcocapnetum baeticae Pérez Latorre y Cabezudo ass. nova } \\
\text { (Asplenietea, Sarcocapnetalia, Sarcocapnion crassifoliae) }\end{array}$} \\
\hline Inventario $n^{\circ}$ & 1 & 2 & 3 \\
\hline Orientación & $\mathrm{N}$ & $\mathrm{N}$ & $\mathrm{N}$ \\
\hline Inclinación $\left({ }^{\circ}\right)$ & 90 & 90 & 90 \\
\hline Altitud $(\mathrm{m})$ & 1100 & 1560 & 1070 \\
\hline Cobertura (\%) & 10 & 10 & 5 \\
\hline Área $\left(\mathrm{m}^{2}\right)$ & 50 & 1 & 15 \\
\hline Litología & Cal. & Cal. & Dol. \\
\hline \multicolumn{4}{|c|}{ Característica de asociación } \\
\hline Sarcocapnos baetica & 1 & 1 & 2 \\
\hline \multicolumn{4}{|c|}{ Características de unidades superiores } \\
\hline Campanula velutina & + & . & + \\
\hline Galium nevadense & . & + & . \\
\hline Leontodon taraxacoides & + & . & . \\
\hline Silene andryalifolia & + & . & . \\
\hline Stachys circinata & . & + & . \\
\hline Chaenorrhinum villosum & . & . & + \\
\hline
\end{tabular}

Localidades.-1: Penón de Ronda. Ronda. Málaga. 2: Bajo el Picacho de Fatalandar. Tolox. Málaga. 3: Sierra de Alcaparaín. Carratraca. Málaga. 
Tabla 14

Rhamno pumili-Saxifragetum granatensis Pérez Latorre y Cabezudo ass. nova saxifragetosum granatensis

galietosum pulvinati Pêrez Latorre y Cabezudo subass. nova (Asplenietea, Potentilletalia, Saxifragion camposii)

\begin{tabular}{|c|c|c|c|c|c|c|c|c|c|c|c|c|c|}
\hline Inventario $\mathrm{n}^{\circ}$ & 1 & 2 & 3 & 4 & 5 & 6 & 7 & 8 & 9 & 10 & 11 & 12 & \\
\hline Orientación & $\mathrm{N}$ & W & NW & NW & $\mathrm{W}$ & W & $\mathrm{N}$ & $\mathrm{W}$ & $\mathrm{N}$ & $\mathrm{N}$ & $\mathrm{N}$ & $\mathrm{N}$ & $\mathrm{E}$ \\
\hline Inclinación $\left({ }^{\circ}\right)$ & 80 & 80 & 70 & 90 & 90 & 80 & 90 & 90 & 90 & 90 & 90 & 90 & 90 \\
\hline Altitud (m) & 1160 & 1320 & 1750 & - & 400 & 1400 & 1710 & 1640 & 1640 & 1560 & 1600 & 1400 & 1670 \\
\hline Cobertura (\%) & 15 & 20 & 25 & 10 & 35 & 20 & 30 & 20 & 40 & 30 & 40 & 30 & 20 \\
\hline Ârea $\left(\mathrm{m}^{2}\right)$ & 5 & 20 & 1 & 4 & 30 & 50 & 2 & 50 & 4 & 10 & 4 & 4 & 3 \\
\hline Litología & Dol. & Dol. & Dol. & Dol. & Cal. & Cal. & Cal. & Cal. & Cal. & Cal. & Cal. & Cal. & Cal. \\
\hline
\end{tabular}

Características y diferenciales de asociación

Saxifraga globulifera granatensis

Silene andryalifolia

Rhamnus pumilus

Erodium cheilanthifolium

Armeria villosa

Característica de subasociación

Galium pulvinatum

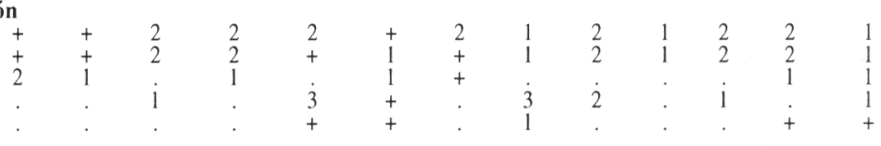

Características de Saxifragion camposii y Potentilletalia

Hieracium baeticum

Chaenorrhinum villosum granatensis

Potentilla petrophila

Galium nevadense

Draba hispanica

Asplenium ruta-muraria

Centranthus nevadensis

Jasione foliosa

Erinus alpinus

Características de unidades superiores

Crepis albida

Asplenium trichomanes

Asplenium ceterach

Sedum dasyphyllum

Melica minuta

Chaenorrhinum villosum

Cystopteris fragilis

Taraxacum obovatum

Asplenium trichomanes pachyrachis

Asplenium trichomanes quadrivalens

Cystopteris dickieana

Sempervivum sp.

Campanula specularioides

Compañeras

Cerastium gibraltaricum

Scabiosa turolensis grosii

Anthyllis vulneraria

Arenaria erinacea

Hormatophylla spinosa

Rhamnus myrtifolius

Stachys circinata

Bunium alpinum macuca

Festuca hystrix

Hedera helix

Campanula velutina

Cephalaria leucantha

Dianthus boissieri

Jasonia glutinosa

Linaria tristis

Prunus mahaleb

Sedum acre

Sedum album

Centranthus macrosiphon

Crambe filiformis

Erinacea anthyllis

Festuca scariosa

Galium album

Galium verticillatum

Scorzonera baetica

Otros táxones: Adiantum capillus-veneris 1, Biscutella frutescens 1, Campanula dichotoma + en 1; Sarcocapnos baetica + en 2; Veronica cymbalaria + en 3 Biscutella sempervirens + en 4; Alyssum simplex +, Anthemis tuberculata +, Arenaria armerina 2, Chaenorrhinum rubrifolium subsp. rubrifolium +, Dactyli glomerata var. hispanica +, Erinacea anthyllis +, Eryngium campestre +, Festuca boissieri +, Festuca capillifolia 1, Helianthemum asperum 1, Helianthemun marifolium + , Helichrysum stoechas,+ Mantisalca salmantica,+ Melica bocquetul +2 , Santolina canescens + , Vicia cracca subsp tenuifolia + en 5 , Linum usitatissimum +, Silene conica subsp conica + en 6, Sisymbrium crassifolium + cn, Erysimum rondae +, Festuca scariosa + , Juniperus phoenicea + , Leucanimemum Taxus baccata + en 11 ; Clematis cirrhosa,+ Paeonia coriacea $+\mathrm{cn} 12$; Helianthemum marifolium + , Helleborus foetidus + , Teucrium lerrouxi + en 13 .

Localidades.-1: Cueva del Agua. Yunquera. Málaga 2: Paredones encima de la garganta de los Hornillos. Yunquera. Málaga. 3: Cerro Alto. Ronda. Málaga. 4: Entre Cañada de En medio y Cañada del Cuerno. Ronda. Málaga. 5: Pto. Cobatillas-Cueva Bermeja. Ronda. Málaga. 6: Cerro de la Yedra. Ronda. Málaga. 7: Cerro Plazoleta, por detrás del Pilar de Tolox. 8: El Picacho de Fatalandar. Tolox. Málaga. 9: El Picacho de Fatalandar. Tolox. Málaga. 10: Bajo el Picacho de Fatalandar. Tolox. Málaga. 11: Tolox. Bajo el Picacho de Fatalandar. Tolox. Málaga. 12: Fuente de los Hornillos. Yunquera. Málaga. 13: Cerro Alcazaba. Tolox. Málaga. 
Tabla 15

Asplenio billotii-Dianthetum lusitani Pérez Latorre y Cabezudo ass. nova

(Asplenietea, Rumicetalia indurati, Rumici-Dianthion)

Inventario $\mathrm{n}^{\circ}$

Orientación

Inclinación $\left({ }^{\circ}\right)$

Altitud (m)

Cobertura (\%)

Área $\left(\mathrm{m}^{2}\right)$

Litología

\section{Características y diferenciales}

Dianthus lusitanus

Asplenium billotii

Cerastium gibraltaricum

Digitalis purpurea tomentosa

Saxifraga granulata

Echinospartum aljibicum

Características de unidades superiores

Umbilicus rupestris

Silene nutans

Polypodium cambricum

Polypodium interjectum

Phagnalon saxatile

Asplenium trichomanes

Cheilanthes maderensis

\section{Compañeras}

Sedum dasyphyllum

Digitalis obscura laciniata

Fumaria capreolata

Galium aparine

Hedera helix

Stachys circinata

Dipcadi serotinum

Antirrhinum graniticum

Sedum tenuifolium

$\begin{array}{cccc}1 & 2 & 3 & 4 \\ \mathrm{E} & \mathrm{NE} & \mathrm{E} & \mathrm{SE} \\ 90 & 90 & 90 & 90 \\ 1300 & 1300 & 860 & 900 \\ 10 & 10 & 10 & 30 \\ 10 & 10 & 10 & 10 \\ \text { Gne. } & \text { Gne. } & \text { Are. } & \text { Gne. }\end{array}$

SE

90

30

10

$\begin{array}{llll}2 & 1 & 1 & 3 \\ + & + & + & 1 \\ + & + & . & 1 \\ . & + & . & . \\ . & + & . & .\end{array}$

3

\section{1}

$$
1
$$

$\begin{array}{lll} & & \\ + & 1 & 1\end{array}$

. $+2+$

t. + t +

. + .

. .101

t

Localidades.- 1: Junto al Peñón del Robledal. Parauta. Málaga. 2: Junto al Peñón del Robledal. Parauta. Málaga. 3: Los Alcornocales. Montejaque. Málaga. 4: Hoyo del Bote. Puerto de la Refriega. Istán. Málaga. 
Tabla 16

Ranunculo macrophylli-Juncetum inflexi Pérez Latorre, Galán de Mera y Cabezudo ass. nova (Molinio-Arrhenaterethea, Plantaginetalia, Agropyro-Rumicion crispi)

\author{
Inventario $\mathrm{n}^{\circ}$ \\ Orientación \\ Inclinación $\left({ }^{\circ}\right)$ \\ Altitud (m) \\ Cobertura $(\%)$ \\ Área $\left(\mathrm{m}^{2}\right)$ \\ Litología
}

$\begin{array}{ccccc}1 & 2 & 3 & 4 & 5 \\ \mathrm{~W} & - & \mathrm{W} & \mathrm{S} & - \\ 10 & 0 & 5 & 5 & 0 \\ 1360 & 1100 & 1100 & 1200 & 1030 \\ 70 & 100 & 100 & 90 & 100 \\ 50 & 40 & 30 & 75 & 50 \\ \text { Cal. } & \text { Cal. } & \text { Marg. } & \text { Cal. } & \text { Cal. }\end{array}$

Características y diferenciales de asociación

Juncus inflexus

Ranunculus macrophyllus

Potentilla reptans

Mentha suaveolens

Festuca arundinacea atlantigena

Carex mairii

Narcissus bugei

\section{Características de unidades superiores}

Scirpus holoschoenus

Agrostis stolonifera

Prunella vulgaris

Trifolium repens

Carex flacca serrulata

Gaudinia fragilis

Juncus articulatus

Holcus lanatus

Plantago major

$\begin{array}{lllll}3 & 2 & 4 & 4 & 5 \\ 3 & + & + & + & 2 \\ + & + & . & 1 & . \\ . & 1 & . & . & + \\ . & . & 1 & 1 & . \\ i & . & + & + & .\end{array}$

\section{Compañeras}

Rorippa nasturtium-aquaticum

Agrostis reuteri

Brachypodium sylvaticum

Equisetum ramosissimum

Galium album

Samolus valerandi

\begin{tabular}{|c|c|c|c|c|}
\hline & 1 & 3 & 3 & 1 \\
\hline & & . & 1 & 2 \\
\hline & + & + & + & \\
\hline & + & . & 1 & 2 \\
\hline 1 & 1 & . & . & . \\
\hline & & + & + & \\
\hline & . & + & 1 & . \\
\hline • & . & + & + & . \\
\hline & & & . & + \\
\hline & . & . & 2 & 1 \\
\hline & . & + & + & . \\
\hline & & 1 & . & . \\
\hline & + & + & . & \\
\hline & . & + & + & \\
\hline & . & + & + & . \\
\hline
\end{tabular}

Otros táxones: Aristolochia longa 1, Bellis sylvestris 1, Hyacinthoides hispanica 1, Iris pseudacorus 1, Piptatherum paradoxum 1, Ranunculus ficaria subsp ficaria 3 , Rhagadiolus edulis + , Rubia peregrina + en 1, Allium sphaerocephalon subsp sphaerocephalon + , Ammoides pusilla + , Anagallis arvensis + , Asperula hirsuta + , Avenula gervaisii subsp arundana + , Avenula gervaisii subsp gervaisii,+ Cleonia lusitanica,+ Diplotaxis catholica + , Elymus repens subsp repens + , Lolium rigidum + , Lythrum junceum + , Melica magnolii + , Melica minuta + , Ornithogalum narbonense + , Phalaris coerulescens,+ Phleum bertolonii 1 , Rapistrum rugosum subsp. rugosum 1, Scrophularia lyrata + en 3; Anagallis tenella,+ Bromus hordeaceus + , Eryngium campestre + , Festuca scariosa + , Juncus hybridus + , Juncus pygmaeus + , Lactuca viminea subsp ramosissima + , Lagurus ovatus + , Linaria tristis + , Trifolium stellatum + en 4 ; Bellis perennis + , Carlina corymbosa + , Scolymus hispanicus + , Veronica cymbalaria + en 5 .

Localidades.- 1:Base Cañada de las Animas. Ronda. Málaga. 2: Cortijo Sabinal Alto. Ronda. Málaga. 3: Afluente del arroyo Taramal. Ronda. Málaga. 4: Fuente del Peñón de Ronda. Ronda. Málaga. 5: Entre los cortijos de Molillo y Colmenarejo. Ronda. Málaga. 
Tabla 17

Elymo repentis-Phalaridetum coerulescentis

Pérez Latorre, Galán de Mera y Cabezudo ass. nova

(Molinio-Arrhenateretea, Phalaridetalia, Gaudinio-Hordion)

Inventario $\mathrm{n}^{\circ}$

Orientación

Inclinación $\left(^{\circ}\right)$

Altitud (m)

Cobertura $(\%)$

Área $\left(\mathrm{m}^{2}\right)$

Litología

Características y diferenciales de asociación

Achillea ageratum

Achillea odorata

Elymus repens

Narcissus bugei

Koeleria vallesiana humilis

Phleum bertolonii

Características de alianza y orden

Gaudinia fragilis

Leontodon tingitanus

Scilla peruviana

Phalaris coerulescens

Poa trivialis

Características de clase

Carex flacca serrulata

Potentilla reptans

Ranunculus macrophyllus

Linum bienne

Lotus corniculatus

Juncus inflexus

Bellis perennis

Agrostis stolonifera

Crepis capillaris

Ononis repens australis

Juncus striatus

Plantago lanceolata

Prunella vulgaris

Trifolium repens

Compañeras

Bellis sylvestris

Convolvulus arvensis

Linum tenue

Lolium rigidum

Ranunculus ficaria

$\begin{array}{cccc}1 & 2 & 3 & 4 \\ - & \text { NW } & - & - \\ 0 & 5 & 0 & 0 \\ 1300 & 1250 & 1300 & 1300 \\ 100 & 100 & 70 & 80 \\ 100 & 100 & 40 & 30 \\ \text { Marg. } & \text { Marg. } & \text { Arc. } & \text { Arc. }\end{array}$

Otros táxones: Allium roseum + , Astragalus macrorhizus + , Festuca capillifolia 1, Galium parissiense + , Hyacinthoides hispanica + , Leuzea conifera + , Lotus glareosus + , Narcissus assoanus subsp. praelongus + , Orchis mascula + , Plantago coronopus subsp. coronopus + , Rumex acetosella subsp. angiocarpus + , Thapsia villosa 1, Trifolium campestre + en 1; Asphodelus macrocarpus subsp rubescens 1, Coronilla scorpioides 1, Doronicum plantagineum 1, Galium baeticum +, Geranium malviflorum +, Romulea ramiflora subsp. ramiflora + , Saxifraga granulata + en 2; Agrostis pourretii,+ Centaurea pullata subsp. baetica + , Galium tunetanum 2, Melica magnolii +, Vicia laxiflora + en 3; Carduus tenuiflorus + , Euphorbia exigua + , Melilotus indica + , Muscari comosum + , Trifolium arvense + , Vicia lutea subsp. cavanillesii 1 en 4.

Localidades.- 1: Proximidades del Cortijo Quejigales, junto al carril de subida a los Pilones. Ronda. Málaga. 2: Camino del Cortijo Quejigales a la cañada del Cuerno. Ronda. Málaga. 3: Proximidades del Cortijo Quejigales. Ronda. Málaga. 4: Alrededores del Cortijo Quejigales. Ronda. Málaga. 


\section{BIBLIOGRAFÍA}

ASENSI A. y S. RIVAS MARTÍNEZ -1976Contribución al conocimiento fitosociológico de los pinsapares de la Serranía de Ronda. Anal. Inst. Bot. Cavanilles 33:239-247.

ASENSI A., B. DÍEZ GARRETAS y F. ESTEVE 1978- Contribución al estudio del Omphalodion brassicaefoliae Rivas Martínez S., Izco J. y Costa M. en el sur de la Península Ibérica. Acta Bot. Malacitana 4:63-70.

BARBERO M. \& P. QUÉZEL -1979- Le probléme des manteaux forestières des PistacioRhamnetalia alaterni en Méditerranée Orientale. Coll. Phytosociologiques VIII:9-20.

BARBERO M. \& P. QUÉZEL - 1990- Les forets méditerranéenes. Problémes posés par leur signification historique, écologique et leur conservation. Acta Bot. Malacitana 15:145-178.

BARBÉRO, M., P. QUÉZEL \& S. RIVAS MARTÍNEZ -1981- Contribution à l'étude des groupements forestiers et préforestiers du Maroc. Phytocoenologia 9:311-412.

BENABID A. \& M. FENNANE - 1994- Conaissances sur la végétation du Maroc: Phytogéographie, phytosociologie et séries de végétation. Lazaroa 14:21-97.

CABEZUDO B., J. MOLERO MESA y A. V. PÉREZ LATORRE -1998- Vegetación de Andalucía in Rodriguez Hiraldo C. (coord.) Tomo III La Flora. (obra completa: Naturaleza de Andalucía). Ed. Giralda. Sevilla.

CEBALLOS L. y C. VICIOSO. - 1933-Estudio sobre la vegetación y flora forestal de la provincia de Málaga. Inst. Forestal de Invest. y Exp. .Madrid.

CUATRECASAS, J. -1929- Estudio sobre la flora y la vegetación del macizo de Mágina. Trabajos del Museo de Ciencias Naturales de Barcelona 12: 5-510.

GALÁN DE MERA A., U. DEIL, H. HAUG y J. A. VICENTE ORELLANA - 1997- Contribución a la clasificación fitosociológica de los pastizales de la provincia de Cádiz (España). Acta Bot. Malacitana 22:147-170.

GÓMEZ MERCADO, F. , J. F. MOTA, J. PEÑAS \& J. CABELLO -1997- Subbetic Natural Park (Córdoba, Spain): habitats and floristic diversity. Lagascalia 19(1): 639-652.

GÓMEZ MERCADO F., F. VALLE TENDERO y J. F. MOTA -1993- Los pastizales de la clase
Festuco-Ononidetea striatae y Nardetea en las montañas calcáreas del sur de España. Colloq. Phytosoc. XXI: 707-722.

LOIDI, J., I. BIURRUN y M. HERRERA GALLASTEGUI -1997-. La vegetación del centro-septentrional de España. Itinera Geobot. 9: 161-618.

LÓPEZ G. -1978- Contribución al conocimiento fitosociológico de la Serranía de Cuenca, II. Anal. Inst. Bot. Cavanilles, 34(2): 597-702.

LÓPEZ GUADALUPE M., G. MARÍN, J. MOLERO y F. ESTEVE - 1982-Contribución al estudio de la Asplenietea rupestria en Andalucía Oriental I: Seselietum vayredani López Guadalupe y Esteve Chueca (as. nova). Trab. del Departamento de Botánica (Granada), 7: 5-10.

LOSA QUINTANA J. M., J. MOLERO MESA y M. CASARES PORCEL - 1986- El paisaje vegetal de Sierra Nevada. Servicio de Publicaciones. Universidad de Granada.

MOLERO MESA, J. y F. PÉREZ RAYA -1987Estudio fitosociológico de los sabinares de Juniperus phoenicea L. en el sector MalacitanoAlmijarense (provincia corológica Bética). Lazaroa 7: 301-306.

MOLINA ABRIL, J. A. -1993-Resumen sintaxonómico de las comunidades vegetales de Francia y España hasta el rango de alianza. Colloques phytosociologiques XXII: 55-110.

NIETO CALDERA, J. M. -1987-Estudio Fitocenológico de las Sierras Tejeda y Almijara. Microfichas. Universidad de Málaga.

NIETO CALDERA, J. M., A. V. PÉREZ LATORRE y B. CABEZUDO -1991-. Biogeografía y series de vegetación de la provincia de Málaga (España). Acta Bot. Malacitana 16(2): 417-436.

NIETO J. M. y B. CABEZUDO -1988- Series de vegetación climatófilas de las sierras Tejeda y Almijara (Málaga-Granada. España) Acta Bot. Malacitana 13:229-260.

NIETO J. M., B. CABEZUDO y M. TRIGO -1989Series de vegetación edafófilas de las sierras Tejeda y Almijara (Málaga-Granada. España). Acta Bot. Malacitana, 14:161-170.

NIETO J. M., B. CABEZUDO, A. V. PÉREZ LATORRE, D. NAVAS, P. NAVAS y Y. GIL 1998-Apuntes para el estudio del paisaje vegetal de la provincia de Málaga in Rebollo M., F. serrano, J. M. Nieto y B. Cabezudo (Eds.). Itinerarios por Espacios Naturales de la 
provincia de Málaga. Servicio de publicaciones. Universidad de Málaga.

NIETO J. M., S. PÉREZ SANZ y B. CABEZUDO. -1988- Datos sobre la vegetación dolomitícola del sector Rondeño (Sierra de Mijas, Málaga, España). Lazaroa 10:35-46.

PÉREZ LATORRE, A. V., A. GALÁN DE MERA, U. DEIL y B. CABEZUDO - 1996- Fitogeografía y vegetación del sector Aljíbico (Cádiz-Málaga, España). Acta Bot. Malacitana 21: 241-267.

PÉREZ RAYA F. -1988- La vegetación supra y oromediterránea nevadense sobre sustratos básicos. Monogr. Fl. y Veg. Béticas 3:135-142. QUÉZEL P. \& M. BARBERO - 1981- Contribution a l'étude des formations pré-steppiques a genévriers au Maroc. Bol. Soc. Brot. Ser. 2, 53(2):1137-1160.

QUÉZEL P.\& M. BARBERO - 1989- Les formations à genévriers rampants du Djurdjura (Algérie). Leur signification écologique, dynamique et syntaxonomique dans une approche globale des cédraies kabyles. Lazaroa 11:85-99.

RIVAS GODAY, S. y RIVAS MARTÍNEZ, S. 1963-. Estudio y clasificación de los pastizales españoles. Ministerio de Agricultura. Madrid.

RIVAS MARTÍNEZ, S. -1964- Esquema de la vegetación potencial y su correspondencia con los suelos en la España Peninsular. Anal. Inst. Bot. Cavanilles 22:343-420.

RIVAS MARTÍNEZ, S., A. ASENSI, J. MOLERO MESA y F. VALLE -1991- Endemismos vasculares de Andalucía. Rivasgodaya 6: 5-76.
RIVAS MARTÍNEZ, S., F. FERNÁNDEZ GONZÁLEZ y J. LOIDI -1998- Check-list of the high syntaxa of Spain and continental Portugal (Iberian Peninsula, balearic and Canary Islands). Pholia Botanica Matritensis 17: 1-23. TALAVERA S., F. J. SALGUEIRO, LI. SÁEZ y B. CABEZUDO -1998- Nota sobre Genista lobelii sensu Willkomm en la Península Ibérica. Acta Bot. Malacitana 23: 272-278.

Aceptado para su publicación en Junio de 1998

Dirección de los autores. Dpto. Biología Vegetal. Facultad de Ciencias. Universidad de Málaga. 29071, Málaga. E-mail: avperez@uma.es; bcabezudo@uma.es 